\title{
Postnatal Expression of Neurotrophic Factors Accessible to Spiral Ganglion Neurons in the Auditory System of Adult Hearing and Deafened Rats
}

\author{
Erin M. Bailey ${ }^{1}$ and Steven H. Green ${ }^{1,2}$ \\ Departments of ${ }^{1}$ Biology and ${ }^{2}$ Otolaryngology, University of Iowa, Iowa City, Iowa 52242
}

\begin{abstract}
Spiral ganglion neurons (SGNs) receive input from cochlear hair cells and project from the cochlea to the cochlear nucleus. After destruction of hair cells with aminoglycoside antibiotics or noise, SGNs gradually die. It has been assumed that SGN death is attributable to loss of neurotrophic factors (NTFs) derived from hair cells or supporting cells in the organ of Corti (OC). We used quantitative PCR (qPCR) to assay NTF expression - neurotrophin-3 (NT-3), BDNF, GDNF, neurturin, artemin, and CNTF-in the OC and cochlear nucleus at various ages from postnatal day 0 (P0) to P90 in control hearing and neonatally deafened rats. NT-3, neurturin, and CNTF were most abundant in the postnatal hearing OC; CNTF and neurturin most abundant in the cochlear nucleus. In the OC, NT-3 and CNTF showed a postnatal increase in expression approximately concomitant with hearing onset. In rats deafened by daily kanamycin injections (from P8 to P16), surviving inner hair cells were evident at P16 but absent by P19, with most postsynaptic boutons lost before P16. NT-3 and CNTF, which normally increase postnatally, had significantly reduced expression in the OC of deafened rats, although CNTF was expressed throughout the time that SGNs were dying. In contrast, neurturin expression was constant, unaffected by deafening or by age. CNTF and neurturin expression in the cochlear nucleus was unaffected by deafening or age. Thus, NTFs other than NT-3 are available to SGNs even as they are dying after deafening, apparently conflicting with the hypothesis that SGN death is attributable to lack of NTFs.
\end{abstract}

Key words: cochlea; deafness; neuronal survival; neurotrophic factor; organ of Corti; spiral ganglion

\section{Introduction}

Spiral ganglion neurons (SGNs) receive input from cochlear hair cells and project from the cochlea to the cochlear nucleus. After destruction of hair cells with aminoglycoside antibiotics or noise, SGNs gradually die (Spoendlin, 1975; Ylikoski et al., 1998). It has been assumed that this is because hair cells provide neurotrophic factors (NTFs) or other stimuli necessary for SGN survival (Green et al., 2008). Consistent with this assumption are studies showing that NTFs can promote SGN survival in vivo after hair cell loss (Shibata et al., 2011). However, SGNs can persist for long periods of time without hair cells: months in rats or guinea pigs (Webster and Webster, 1981; Koitchev et al., 1982; Bichler et al., 1983), years in cats (Leake and Hradek, 1988), and decades in humans (Nadol et al., 1989; Nadol, 1997). Moreover, in a murine model of thiamine deprivation, SGNs are able to survive for months in the absence of inner hair cells (IHCs; Zilberstein et al.,

\footnotetext{
Received March 13, 2014; revised July 29, 2014; accepted Aug. 18, 2014.

Author contributions: E.M.B. and S.H.G. designed research; E.M.B. performed research; E.M.B. and S.H.G. analyzed data; E.M.B. and S.H.G. wrote the paper.

This study was supported National Institutes of Health Grants R01 DC02961, DC DC009405, and P30 DC010362 (S.H.G.) and National Research Service Award Grant F31 DC011680 (E.M.B.). We thank Drs. Dan Eberl, Bernd Fritzsch, Marlan Hansen, John Manak, Josep Comeron, and members of the Green laboratory for valuable comments. We thank Catherine Kane for technical assistance.

The authors declare no competing financial interests.

Correspondence should be addressed to Steven H. Green, Department of Biology, University of lowa, 143 Biology Building, lowa City, IA 52242-1324. E-mail: steven-green@uiowa.edu.

DOI:10.1523/JNEUROSCI.1014-14.2014

Copyright $\odot 2014$ the authors $\quad 0270-6474 / 14 / 3413110-17 \$ 15.00 / 0$
}

2012). Such observations are inconsistent with the hypothesis that loss of hair cell-derived NTFs is the proximate cause of SGN death.

Here we systematically investigate the spatiotemporal pattern of expression of NTFs available to SGNs in hearing and deaf rats. (1) Neurotrophin-3 (NT-3) is produced in hair cells and adjacent supporting cells (Sugawara et al., 2007) and shown to support SGN survival in vitro (Malgrange et al., 1996; Hegarty et al., 1997) and in vivo after hair cell loss (Ernfors et al., 1996; Staecker et al., 1996). (2) Like NT-3, BDNF promotes SGN survival in vitro (Malgrange et al., 1996; Hegarty et al., 1997) and in vivo (Nakaizumi et al., 2004; Rejali et al., 2007), but unlike NT-3, expression of BDNF declines postnatally (Ylikoski et al., 1993). (3) GDNF family ligands (GFLs) — GDNF, neurturin, and artemin —are present in the sensorineural epithelium/lateral wall of the adult rat cochlea (Stöver et al., 2000) and support SGN survival in vitro (Ylikoski et al., 1998; Wei et al., 2007). GDNF (Ylikoski et al., 1998; Yagi et al., 2000; Kanzaki et al., 2002) and artemin (Warnecke et al., 2010) support SGN survival in vivo. (4) CNTF has been shown to promote SGN survival in vitro alone (Whitlon et al., 2007) or in combination with neurotrophins (Staecker et al., 1995; Hartnick et al., 1996).

Using qPCR, we investigated expression of these factors in the organ of Corti (OC) and the cochlear nucleus of deafened and hearing rats up to postnatal day 90 (P90). NT-3, CNTF, and neurturin are the most abundantly expressed but with distinct spatial and temporal patterns. NT-3 and CNTF are upregulated 
postnatally in the OC, but after hair cell loss, NT-3 expression remains low and CNTF expression declines slowly. Neurturin is expressed at a near constant level in the postnatal OC, and its expression is not affected by hair cell loss. CNTF and neurturin remain expressed in the cochlear nucleus. In addition to illustrating the complexity of NTF expression regulation in the cochlea, these observations weaken the assumption that SGNs die primarily because of lack of neurotrophic support after deafening.

\section{Materials and Methods}

Animals, deafening, and verification. Pregnant Sprague Dawley rats were purchased from Harlan Laboratories. The day of birth was designated as P0. Both male and female rats were used for this study. All procedures were approved by the University of Iowa Institutional Animal Care and Use Committee and conform to National Institutes of Health guidelines.

Neonatal rats were deafened as described previously (Alam et al., 2007) by daily systemic kanamycin injections ( $400 \mathrm{mg} / \mathrm{kg}$ ) from P8 to P16, taking advantage of the particular sensitivity to aminoglycoside at this age (Carlier and Pujol, 1980). As we have reported previously (Alam et al., 2007), this method reliably eliminates IHCs in rats. In the present study, loss of hair cells was further verified by qPCR assay of myosin VIIA, a hair cell-specific transcript, in every sample. In addition, a subset of cochleae were used for histological verification (see below) of hair cell destruction rather than for obtaining RNA. The histological assessment confirms that this protocol reliably eliminates all or nearly all IHCs by P23; some cochleae had a small number of IHCs in the apex. Because the histological and qPCR analyses are expensive and time consuming, the kanamycin-treated rats were tested first to ensure lack of detectable auditory brainstem response (ABR) at $96 \mathrm{~dB}$ SPL (click stimuli, $1-70 \mathrm{kHz}$ stimulus range).

In older rodents, susceptibility to aminoglycosides is reduced relative to $\mathrm{P} 8 \mathrm{-P} 16$, requiring a different deafening protocol than that used for the neonates. Coadministration of a loop diuretic, such as furosemide, increases hair cell susceptibility to aminoglycosides, and Tan and Shepherd (2006) have described an effective such strategy for deafening adult rats. We adapted their protocol for use in these experiments. Specifically, female Sprague Dawley rats weighing from 240 to $260 \mathrm{~g}$ (3-4 months old) were briefly anesthetized using a mixture of oxygen $(25 \%)$ and $\mathrm{CO}_{2}$ (75\%) gas. Gentamicin sulfate (420 mg/kg; catalog \#G1914; Sigma) and furosemide (200 mg/kg; catalog \#F4381; Sigma) were prepared separately in $2 \mathrm{ml}$ of sterile-filtered $0.9 \%$ saline solution and warmed to $37^{\circ} \mathrm{C}$ before injection. Gentamicin sulfate was first injected subcutaneously in the lateral abdominal side, followed immediately by injection of furosemide in the dorsal neck area. After recovery from anesthesia, rats were returned to the colony and monitored closely for dehydration; if necessary, rats were injected one to two times daily with $3-4 \mathrm{ml}$ of warm $0.9 \%$ sterile saline.

Immunohistochemistry. For fluorescently labeling hair cells and SGNs of neonatally deafened rats and age-matched controls, the following protocol was used. Hearing control and deafened littermates were anesthetized with a ketamine $(40 \mathrm{mg} / \mathrm{kg}) / x y l a z i n e ~(4 \mathrm{mg} / \mathrm{kg})$ mixture and immediately killed by transcardial perfusion of PBS, $\mathrm{pH} 7.4$, followed by $4 \%$ paraformaldehyde (PFA) in $0.1 \mathrm{~m}$ phosphate buffer at P16, P18, P19, $\mathrm{P} 21$, and $\mathrm{P} 23$. Temporal bones were removed and postfixed in 4\% PFA for $1 \mathrm{~h}$ at room temperature. Temporal bones were decalcified for $3 \mathrm{~d}$ in 0.12 M EDTA, which was changed daily. After decalcification, cochleae were removed, and the bony capsule and spiral ligament were dissected away and cut into apical, middle, and basal whole-mount preparations. Cochlear preparations were permeabilized with $0.8 \%$ Triton X-100 in PBS for $2 \mathrm{~h}$, followed by incubation in blocking buffer (PBS plus $2 \%$ BSA plus $5 \%$ normal goat serum plus $0.1 \% \mathrm{NaN}_{3}$ ) overnight at $4^{\circ} \mathrm{C}$. Primary antibodies in blocking buffer were then added for $2 \mathrm{~d}$ at $4^{\circ} \mathrm{C}$. After application of primary antibodies, preparations were washed three times for 15 min each in PBS and incubated in blocking buffer with fluorescently labeled secondary antibodies (Alexa Fluor conjugates; 1:400; Invitrogen) for $1 \mathrm{~d}$ at $4^{\circ} \mathrm{C}$. Primary antibodies used for this study included the following: "neuronal mix," combined mouse anti-NF heavy chain [NF200; 1:400; catalog \#N0142; Sigma; Research Resource Identifier (RRID):
AB_477257], anti-TUJ1 (1:400; catalog \#T8660; Sigma; RRID: AB_477590), and anti-NF medium chain (2H3; 1:400; Developmental Studies Hybridoma Bank, University of Iowa; RRID: AB_531793) to label the SGNs; and combined rabbit anti-myosin VI (1:400; catalog \#KA-15; Sigma; RRID: AB_260563), anti-myosin VIIa (1:400; catalog \#25-6790; Proteus; RRID: AB_10015251), and anti-calretinin (1:400; catalog \#AB5054; Millipore Bioscience Research Reagents; RRID: AB_2068506) to label hair cells.

A modified protocol was used for fluorescently labeling hair cells and SGNs of adult (240-260 g) deafened and control rats. Rats were anesthetized as above and killed by decapitation 2 weeks after gentamicin/furosemide treatment. Temporal bones were quickly removed and placed in ice-cold PBS for dissection. One cochlea from each rat was used to obtain RNA (see below), whereas the other was used for histological verification of hair cell destruction. For the latter, the bony capsule and spiral ligament were dissected away from the cochlea, and the remaining tissue was immediately placed in $4 \%$ PFA for 2-3 h. After fixation, cochleae were decalcified in $0.12 \mathrm{~m}$ EDTA for 8-10 h, replacing EDTA every 30-60 min. The cochleae were permeabilized for $2 \mathrm{~h}$ in $1 \%$ Triton X-100. Labeling proceeded as above for neonatally deafened rats. Primary antibodies used for this study were as above except that anti-calretinin was not used.

Synaptic ribbon and postsynaptic density (PSD) labeling was performed as described by Wang and Green (2011) for neonatal explant culture but modified extensively here for use in cochleae freshly removed from adult animals. Hearing control and deafened littermates were anesthetized as above and killed by decapitation at P12 and P16. Temporal bones were quickly removed and placed in ice-cold PBS for dissection. Portions of the bony capsule and surrounding tissue were dissected away to expose the underlying cochlea. The remaining tissue was immediately transferred, using fine-tip forceps, to a 96-well tissue culture plate (cata$\log \# 353072$; BD Falcon) containing 4\% PFA for 10-15 min, washed in PBS, and decalcified in $0.12 \mathrm{M}$ EDTA for $3-4 \mathrm{~h}$, replacing EDTA every $30-60 \mathrm{~min}$. The cochleae were permeabilized for $2 \mathrm{~h}$ in $1 \%$ Triton $\mathrm{X}-100$, incubated in $50 \mathrm{~mm} \mathrm{NH}_{4} \mathrm{Cl}$ for $1.5 \mathrm{~h}$, followed by blocking in $20 \%$ horse serum in PBS for an additional $1.5 \mathrm{~h}$. For immunofluorescence imaging, the cochleae were incubated sequentially in primary and secondary antibodies diluted in $1 \%$ horse serum in PBS, primary antibodies for $24-48$ $\mathrm{h}$ at $4^{\circ} \mathrm{C}$, and secondary antibodies (Alexa Fluor conjugates; 1:400; Invitrogen) for $24 \mathrm{~h}$ at $4^{\circ} \mathrm{C}$. After immunolabeling, the remaining tissue was removed from the 96-well tissue culture plate and transferred to a plastic dish for additional dissection. The remaining bony capsule and spiral ligament was removed, and the remaining cochlea was divided into apical, middle, and basal whole-mount preparations using a number 11 scalpel blade. Primary antibodies used for this study were mouse antiNF200 to label the SGNs and combined rabbit anti-myosin VI and antimyosin VIIa to label hair cells (see above); anti-PSD-95 (1:200; catalog \#MAB1596; Millipore; RRID: AB_2092365) to label PSDs in SGNs; and anti-C-terminal binding protein 2 (CTBP2; 1:200; catalog \#612044; BD Biosciences; RRID: AB_399431) to label ribbon synapses in hair cells.

Imaging and quantitation. Fluorescently labeled cochlear preparations were imaged using a Leica TCS P2 Spectra confocal system with a Leica DMIRE2 inverted microscope. Hair cell images were obtained with a $20 \times, 0.70$ numerical aperture (NA) dry objective with a $3 \times$ zoom. Synapse images for quantitation were obtained with a $63 \times, 1.20 \mathrm{NA}$ waterimmersion objective with a $3 \times$ zoom. Optical sections in the $x-y$ plane were imaged and recorded at $0.3 \mu \mathrm{m}$ steps in the $z$-axis to generate a $z$-stack of images that can be projected onto a single plane ( $z$-projection). To count IHCs, $z$-projection images of myosin VI/myosin VIIa/ calretinin-labeled IHCs were viewed in NIH ImageJ software. The length of OC for each preparation was measured in millimeters. For control cochleae, five $100 \mu \mathrm{m}$ sections of the OC were selected, and the number of IHCs per section was counted. The sections were then averaged to estimate the number of IHCs per preparation. For deafened cochleae, all IHCs were counted.

Immunoreactive synaptic puncta were counted using an optical disector method as we described previously (Wang and Green, 2011). The entire z-stack was viewed in NIH ImageJ software, slice by slice. Each immunofluorescent punctum was counted in the first slice (optical section) in which it appeared in focus, and the location was marked to 
Table 1. Forward and reverse primer sequences for qPCR

\begin{tabular}{|c|c|c|c|c|}
\hline Gene name & Primer sequence & Accession number & Amplicon length (bp) & qPCR efficiency (\%) \\
\hline \multicolumn{5}{|l|}{ NT-3 } \\
\hline Forward & 5'-CGTGCGTGTGATGCTACCT-3' & \multirow[t]{2}{*}{ NM_031073 } & \multirow[t]{2}{*}{99} & \multirow[t]{2}{*}{98.2} \\
\hline Reverse & $3^{\prime}$-GGCTCTCACTGTCACACACTGA-5' & & & \\
\hline Forward & $5^{\prime}$-CACCAGGTGAGAAGAGTGATGAC-3' & \multirow[t]{2}{*}{ EF_125690 } & \multirow[t]{2}{*}{72} & \multirow[t]{2}{*}{95.5} \\
\hline Reverse & 3'-GTCATCACTCTTCTCACCTGGTG-5' & & & \\
\hline \multicolumn{5}{|l|}{ GDNF } \\
\hline \multicolumn{5}{|l|}{ Neurturin } \\
\hline Forward & 5'-CGTGCGTGTGATGCTACCT-3' & \multirow[t]{2}{*}{ NM_053399 } & \multirow[t]{2}{*}{73} & \multirow[t]{2}{*}{94.1} \\
\hline Reverse & 3'-TGTGAATTCAGTTCTCCTGAAAGT-5' & & & \\
\hline \multicolumn{5}{|l|}{ Artemin } \\
\hline Forward & $5^{\prime}$-CAGAGCCTGGAAAGATGACC-3' & \multirow[t]{2}{*}{ NM_053397 } & \multirow[t]{2}{*}{65} & \multirow[t]{2}{*}{97.7} \\
\hline Reverse & 3'-AGAGCTGGGATCCATGAACA-5' & & & \\
\hline Forward & 5'-GCAGTACAAGTTACTGGAGCCTGTT-3' & \multirow[t]{2}{*}{ XM_341815 } & \multirow[t]{2}{*}{141} & \multirow[t]{2}{*}{97.4} \\
\hline Reverse & 3'-GCCACCAGAGCTTTTGAGATAGACT-5' & & & \\
\hline \multicolumn{5}{|l|}{ GAPDH } \\
\hline Forward & 5'-TCTACTGGCGTCTTCACCACCA-3' & \multirow[t]{2}{*}{ NM_017008 } & \multirow[t]{2}{*}{559} & 97.4 \\
\hline Reverse & 3'-AGGAGACAACCTGGTCCTCAGT-5' & & & \\
\hline PGK1 & & & & \\
\hline Forward & 5'-ATGCAAAGACTGGCCAAGCTAC-3' & NM_053291 & 104 & 98.5 \\
\hline Reverse & $3^{\prime}$-AGCCACAGCCTCAGCATATTTC-5' & & & \\
\hline Myosin VIla & & & & \\
\hline Forward & 5'-GCGGGCATTGTCTACTATGAG-3' & NM_153473 & 62 & \\
\hline Reverse & 3'-CCATGCAGGGTGTCTCTGT-5' & & & \\
\hline
\end{tabular}

Forward and reverse primer sequences for qPCR were obtained from the Roche Universal Probe Library. Also shown are the GenBank accession numbers for the genes, the predicted size of the amplicons, and the efficiency of the qPCR for each primer pair.

prevent it being counted again. The total number of synaptic puncta counted in each image was divided by the total number of IHCs in the image to calculate the number of puncta per hair cell.

Real-time qPCR. For tissue isolation from neonatally deafened rats and hearing control littermates, the animals were cold-anesthetized (ages P6 or younger) or heavily anesthetized with ketamine/xylazine as above (ages older than P6) and killed by live decapitation at P0, P6, P12, P16, P23, P32, P60, and P88-P90. Temporal bones and brainstems were removed and placed in ice-cold PBS, $\mathrm{pH}$ 7.4, for dissection. The bony capsule and spiral ligament were dissected away from the cochlea. The remaining tissue was divided into apical and basal portions, and the OC was separated from the spiral ganglion. Cochlear nuclei were dissected from the brainstem. Immediately after dissection, tissues were placed into TRIzol (Invitrogen), homogenized using a pellet pestle (RPI), flash frozen in liquid nitrogen, and stored at $-80^{\circ} \mathrm{C}$.

For adult deafened rats and hearing control littermates, tissue isolation was performed as in neonatally deafened rats with some modifications. Adult deafened rats (240-260 g) were heavily anesthetized as above and killed by live decapitation 2 weeks after injection of gentamicin sulfate and furosemide. After removal of the bony capsule and spiral ligament, the remaining tissue was left intact while the OC was separated from the spiral ganglion. Complete OCs were placed into lysis buffer (Buffer RLT; Qiagen), homogenized using a pellet pestle (RPI), flash frozen in liquid nitrogen, and stored at $-80^{\circ} \mathrm{C}$.

Total RNA was extracted from OCs and cochlear nuclei using an RNeasy mini kit (Qiagen). On-column DNase I treatment was performed according to the Qiagen protocol. Immediately after isolation, RNA was reverse transcribed to cDNA using SuperScript II Reverse Transcriptase (Invitrogen). qPCR was completed using SYBR Green I Master Mix (Roche) on a Roche Light Cycler 480 with oligonucleotide primers purchased from Integrated DNA Technologies. Forward and reverse primer sequences (Table 1) for $\mathrm{qPCR}$ were obtained from the Roche Universal Probe Library Assay Design Center (http://lifescience.roche.com/shop/CategoryDisplay?
catalogId $=10001 \&$ tab $=$ \&identifier $=$ Universal + Probe + Library\&langId $=-1)$ and confirmed by sequencing PCR products.

Negative controls were reactions lacking reverse transcriptase and are designated - RT. Similarly prepared cDNA from P6 rat brain was used for positive controls. Relative RNA expression levels were determined by normalization to an S16 reference transcript. Two additional reference transcripts, GAPDH and phosphoglycerate kinase 1 (PGK1), were also used but the S16/GAPDH and S16/PGK1 ratios were constant for all ages and conditions.

Table 1 also shows the GenBank accession numbers for the genes, the predicted size of the amplicons, and the efficiency of the qPCR for each primer pair determined from the amplification curves (fluorescence as a function of cycle number) using the following equation: Efficiency = $10^{-1 / m}-1$, where $m$ is the slope of the standard curve (Rasmussen, 2000).

Efficiencies were $>1.9$ for all primer pairs. Because we could not obtain sufficient template from the samples, an efficiency calculation was not performed for the myosin VIIa primers. Representative examples of amplification curves for each of the NTFs assayed-NT-3, CNTF, GDNF, BDNF, neurturin, and artemin-are shown in Figure 1. Each example shows amplification curves for samples from hearing control and deafened P23 rat apical OCs run in parallel with S16 primers.

Comparisons of NTF transcript levels among different time points, locations, or experimental conditions were made using $\mathrm{qPCR}$ results normalized to the S16 reference transcript. Statistical analyses for qPCR data as well as hair cell and synapse counts were done using GraphPad software.

\section{Results}

Hair cell death after neonatally administered kanamycin

In our deafening protocol, daily kanamycin injections begin at P8 and continue through P16. We could confirm by ABR measurement at P16 that no wave 1 was detectable at sound levels as high 

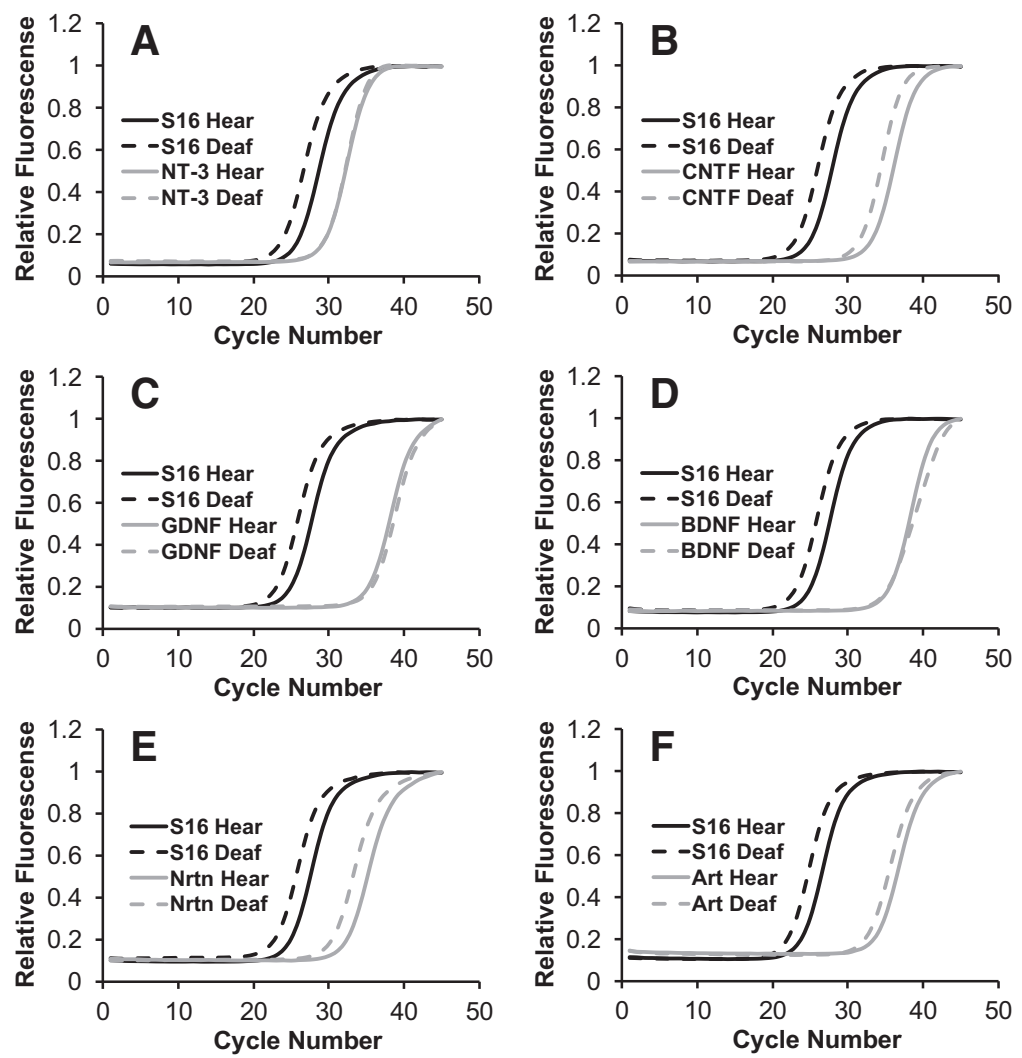

Figure 1. Examples of real-time qPCR amplification curves of all six NTF transcripts assayed, paired with parallel measurements of the reference gene S16 transcripts, in OCs from P23 control hearing (Hear) and kanamycin-treated deafened (Deaf) P23 rats. $\boldsymbol{A}$, NT-3; $\boldsymbol{B}$, CNTF; $\boldsymbol{C}$, GDNF; $\boldsymbol{D}$, BDNF; $\boldsymbol{E}$, neurturin; $\boldsymbol{F}$, artemin.

as $96 \mathrm{~dB}$ SPL in kanamycin-treated rats, implying that few, if any, functional hair cells remain by that time. However, there remained the possibility that hair cells may still be present, even if nonfunctional, and could still be synthesizing NTFs. To establish exactly when hair cells are lost in this protocol, we killed rats at P16, P18, P19, P21, and P23. From these rats, we removed the OCs with the spiral ganglion attached, immunolabeled the hair cells with combined anti-myosin VI, myosin VIIa, and anti-calretinin antibodies, and immunolabeled the SGNs with anti-highmolecular-weight neurofilament (NF200) antibodies. We counted the surviving IHCs and assessed the state of the peripheral SGN axons. Representative images are shown in Figure 2, and the counts of IHCs are plotted in Figure 3.

In cochleae from rats at P16, the final day of the nine days of kanamycin injections, no outer hair cells are evident in the P16 base or middle turn (Fig. $2 B, C, G, H$ ), although some outer hair cells remain in the apex (Fig. $2 M, N$ ). Outer hair cells are absent from the entire cochlea in kanamycin-treated rats at later ages (Fig. 2). With regard to IHCs, despite the absence of an ABR (96 dB SPL) at P16, many surviving IHCs are observed at P16 in all regions of the cochlea, although there is variability in the extent of IHC loss among rats (Figs. $2 B, C, G, H, M, N$, Figs. 3). Specifically, in the basal and middle regions of the cochleae, the number of IHCs was much lower in some kanamycin-treated P16 rats than in P16 control rats (Fig. 2C,H), whereas in other kanamycintreated rats, the number was only slightly reduced (Fig. $2 B, G$ ); the corresponding counts are shown in Figure $3, B$ and $C$. In all cochleae, little IHC loss had occurred in the apex by P16: the number of apical IHCs at P16 is similar to the number in control undeafened P16 rats (Fig. 3D). By P18/P19, IHC loss is evident even in the apical region in all cochleae, but there is considerable variability among rats in IHC number in all three turns (Fig. 3). For examples, compare Figure $2, D / E, I / J$, and $O / P$. By P18, IHCs are absent in all cochlear regions in nearly all cochleae (Fig. 3), although we did encounter a single outlier at P19 in which many hair cells were present in both cochleae of the rat despite no detectable ABR at $96 \mathrm{~dB}$. Note that the variability is mainly among rats; the two cochleae from the same rat are similar with respect to IHC number.

SGN peripheral axons can be observed extending to inner and outer hair cell regions of the $\mathrm{OC}$ at all ages, even at P21/P23 when few, if any, IHCs remain. Indeed, peripheral axons extending to the OC label more intensely at P23 than at earlier ages (Fig. $2 R$ ), possibly because demyelinated fibers label more readily than myelinated fibers within the habenula perforata with our protocol. The presence of peripheral axons after loss of hair cells suggests that hair cell-derived NTFs are not necessary for maintenance of the peripheral axon and that factors derived from other sources, presumably supporting cells in the sensory epithelium, will suffice.

In summary, with this deafening protocol, outer hair cells are rapidly lost during the period of kanamycin treatment; IHCs are lost more slowly with variability among rats in the rate at which hair cells are lost. Most IHCs are still present at the end of the period of kanamycin treatment, P16, and are lost between $\mathrm{P} 16$ and P18. Because no ABR is detectable in kanamycin-treated rats at $\mathrm{P} 16$, IHCs still surviving at that time are unable to generate a neural response.

\section{Synapse loss after kanamycin}

If lack of detectable ABR in all P16 kanamycin-treated rats is not correlated with loss of hair cells, an alternative possibility is that it is attributable to loss of IHC synapses. We detected synapses by labeling the presynaptic ribbons with anti-CTBP2 (Khimich et al., 2005; Wang and Green, 2011) and the PSDs with anti-PSD-95 (Bao et al., 2004; Wang and Green, 2011). Because PSD-95 immunoreactivity is highly sensitive to fixation, the cochlea were rapidly dissected immediately after the animals were killed, fixed briefly in vitro, labeled with primary and secondary antibodies, and imaged on the confocal microscope. Although this protocol preserved the morphology and immunoreactivity of the IHC synapses and allowed imaging and counting of the PSDs, it did result in some physical distortion of the tissue in some preparations, mainly in the outer hair cell region, as can be noted in the images (Fig. 4).

Figure $4 A-L$ shows representative examples of CTBP2- and PSD-95-labeled preparations from apical, middle, or basal regions of the OCs of $\mathrm{P} 16$ kanamycin-treated or control rats. Ribbons (CTBP2-immunoreactive puncta) and PSDs (PSD-95immunoreactive puncta) were counted in stacks of confocal images, as described in Materials and Methods, and the quantitation is presented in Figure $4 M$. As shown, the number of ribbons 


\section{Basal}
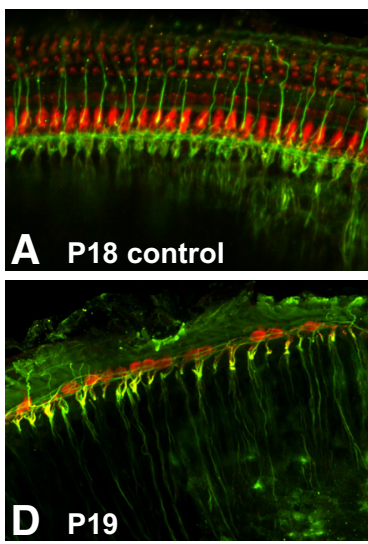

Middle
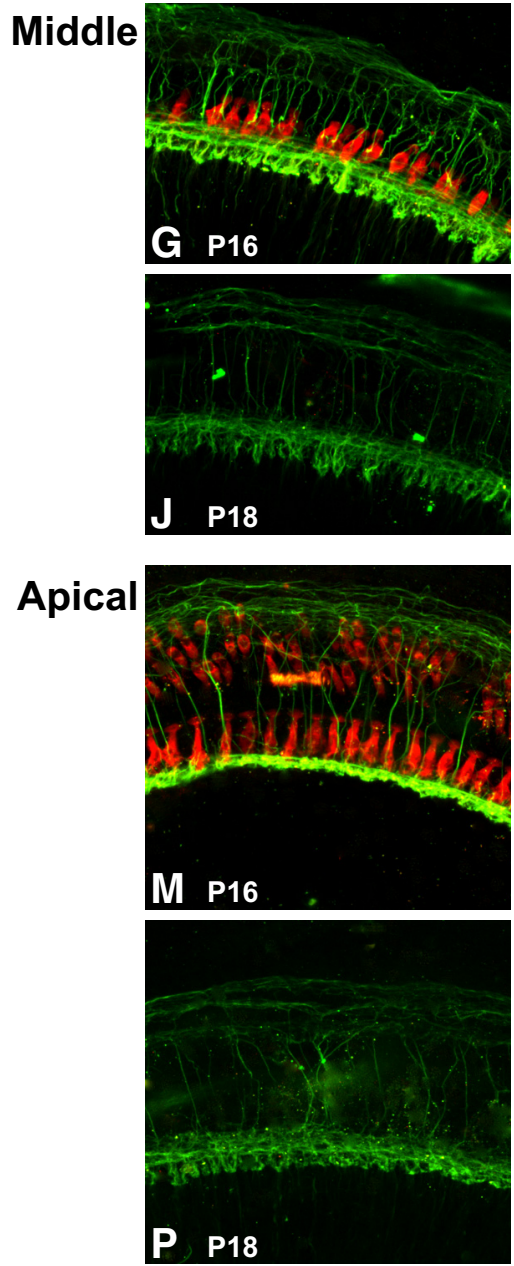
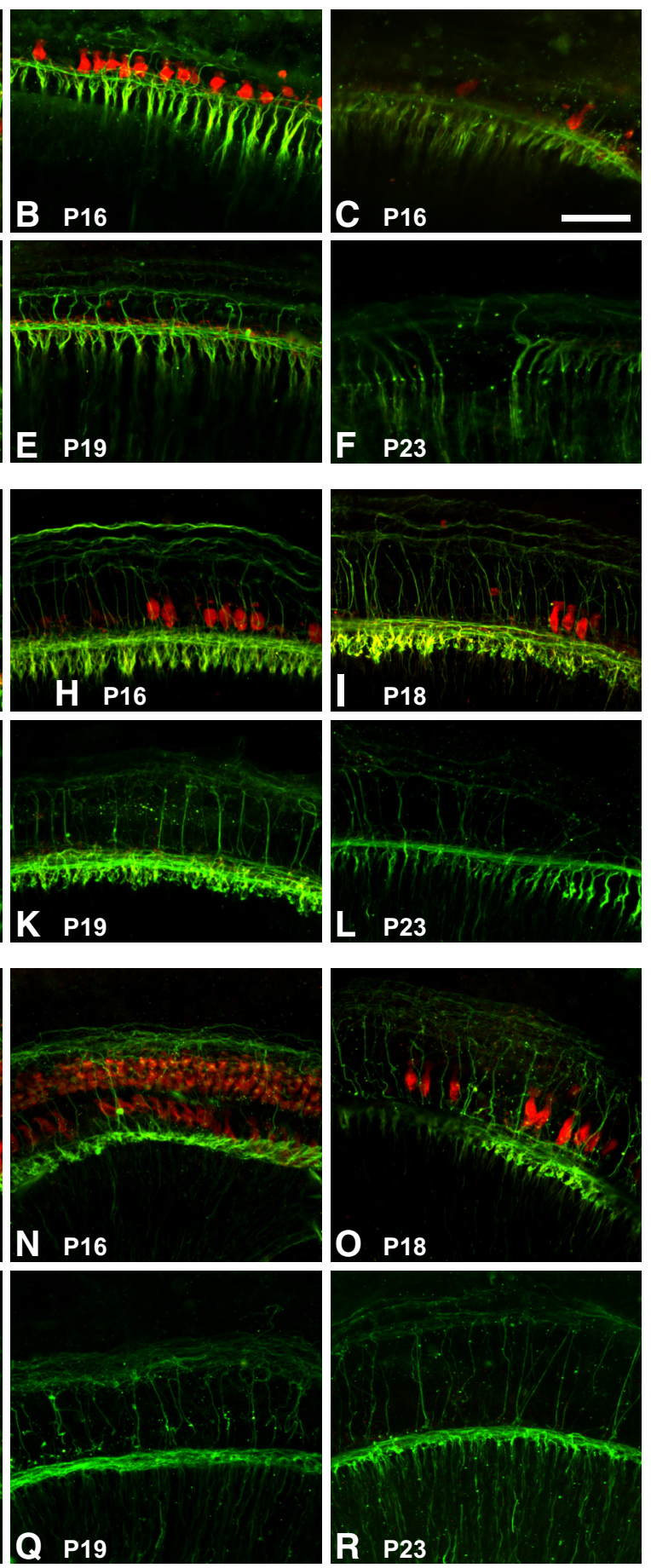

Figure 2. Representative examples of OCs from control hearing and deafened rats at P16, P18, P19, P21, and P23 showing hair cells and their innervation. As described in Materials and Methods, portions of the $O C$, with spiral ganglion attached, were removed and immunolabeled with combined rabbit anti-myosin VI, anti-myosin VIla, and anti-calretinin (red) antibodies, and SGNs were immunolabeled with chicken anti-NF200 (green) antibody. Shown are z-projections of confocal microscope z-stacks of entire whole mounts. Scale bar, $50 \mu \mathrm{m}$. $A$, P 18 hearing control whole-mount preparation showing the one $\mathrm{HHC}$ row and three outer hair cell rows and the characteristic dense innervation of the hair cells. $\boldsymbol{B}-\boldsymbol{F}$, Whole mounts of the basal cochlear region of kanamycin-treated rats at the indicated time points showing examples of $\mathrm{P} 16$ cochleae from different rats in which basal hair cells remain present $(\boldsymbol{B})$ or are mostly lost $(\boldsymbol{C})$ and $\mathrm{P} 19$ cochleae in which basal hair cells remain $(\boldsymbol{D})$ or are lost $(\boldsymbol{E})$. By $P 23$, no hair cells are detectable in the base $(\boldsymbol{F}) . \mathbf{G}-\boldsymbol{L}$, Preparations of the middle cochlear region of kanamycin-treated rats at the indicated time points showing examples of $P 16$ cochleae from different rats in which most $(\boldsymbol{G})$ or only some $(\boldsymbol{H})$ hair cells remain present and P18/P19 cochleae in which some hair cells remain $(\boldsymbol{I})$ or in which no middle region hair cells remain $(\boldsymbol{J}, \boldsymbol{K})$. By P23, no hair cells are detectable in the middle region $(\boldsymbol{L}) \cdot \boldsymbol{M}-\boldsymbol{R}$, Preparations taken from the apical region of kanamycin-treated rats at the indicated time points showing examples of P16 cochleae from different rats in which all $(\boldsymbol{M})$ or most $(\boldsymbol{N})$ apical hair cells remain and P18/P19 cochleae in which some hair cells remain $(\mathbf{O})$ or in which no apical hair cells remain $(\boldsymbol{P}, \mathbf{Q})$. By P23, no hair cells are detectable in the cochlear apex $(\boldsymbol{R})$.

within and the number of PSDs on IHCs is unchanged at P12 during kanamycin treatment. However, by P16, the number of ribbons within and the number of PSDs on surviving IHCs is significantly reduced throughout the cochlea after kanamycin treatment. The reduction in the number of PSDs is greater than the reduction in the number of ribbons (although the difference is not significant in the apex) so that there are many ribbons in surviving IHCs that lack an apposing PSD. We noted similar 

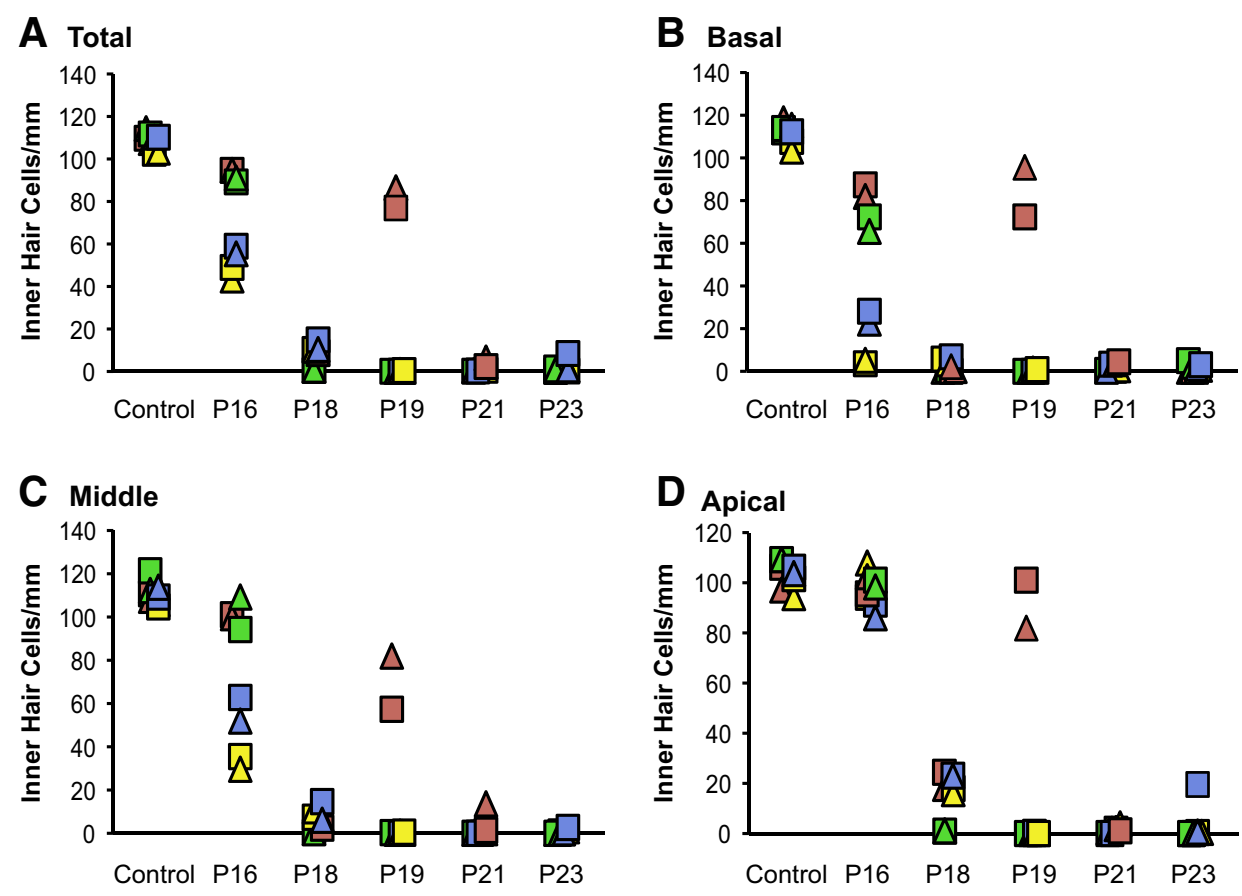

Figure 3. Quantification of inner hair cell loss after kanamycin treatment. Four kanamycin-treated rats were killed at each time point (P16, P18, P19, P21, and P23) to provide eight cochleae. Control undeafened rats were killed at P16. At each time point, each of the four rats is represented by a different color, and the two cochleae from the same rat are distinguished by different shapes (squares or triangles). Some symbols are deliberately horizontally offset slightly so that overlapping symbols may be easily viewed. Values are graphed as hair cells per millimeter. $\boldsymbol{A}$, Quantification of total hair cell loss after kanamycin treatment. $\boldsymbol{B}-\boldsymbol{D}$, Quantification of hair cell loss in the basal, middle, and apical regions of the cochlea, respectively. IHCs are lost in all turns by P21.

persistence of ribbons in the absence of PSDs in hair cells in organotypic cochlear cultures exposed to excitotoxic trauma (Wang and Green, 2011). In the middle and basal turns, PSDs are absent on nearly all surviving hair cells. Thus, aminoglycoside exposure results in loss of functional synapses before loss of IHCs. This could account for the loss of detectable ABR before complete loss of hair cells.

\section{NTF expression in the postnatal OC}

The following results involve comparisons of NTF gene expression between control hearing rats and rats in which we used kanamycin treatment to eliminate hair cells. To this end, we used real-time qPCR to assay NTF expression at various ages, P12P90, in OCs from rats in which the hair cells had been eliminated by postnatal exposure to kanamycin, as well as in littermate control hearing rats. We also assayed NTF expression in OCs from rat pups before hearing onset, at P0 and P6. The time course, from P0 through P90, was chosen because this includes postnatal maturation and hearing onset, as well as the period of time over which $\sim 90 \%$ of SGNs die after neonatal kanamycin exposure in the rat (Alam et al., 2007). Thus, we can determine which NTFs are present during the time that SGNs are dying and better understand the NTF requirements of SGNs.

Expression of NTFs in rat OCs was assayed using real-time qPCR and normalized to ribosomal protein S16. At least three independent repetitions were performed for each age (see Figs. 6, Figs. 7). In each such individual biological repeat, we assayed NTF expression in pooled OCs from three to six deafened rats of the indicated ages and in pooled OCs from three to six hearing control littermates. Results are presented as normalized expression levels, and the ratio of expression in deaf and hearing rats is also shown. NTF mRNA was normalized to that of ribosomal protein S16, as described in Materials and Methods. For all NTFs other than basal BDNF, values obtained were significantly different $(p<0.05$, Mann-Whitney test) from the no reverse transcriptase $(-\mathrm{RT})$ control at all ages in apical and basal halves.

We ask here whether hair cells need to be present for postnatal expression of NTFs in the OC. Loss of hair cells in kanamycintreated rats was verified histologically in the set of cochleae used for Figures 2 and Figures 3. This was correlated with lack of detectable ABR in each rat used. This implies that lack of detectable ABR indicates loss of hair cells. Because hair cell loss cannot be verified histologically in OCs used to obtain RNA, we instead indirectly verified hair cell loss by ABR. Any kanamycin-treated rats showing detectable ABR at $96 \mathrm{~dB}$ SPL were not used further. We further verified hair cell loss by qPCR assay of myosin VIIa mRNA, a hair cell-specific transcript, in all apical and basal halves of OCs used for NTF assays. In all experiments, myosin VIIa mRNA was significantly reduced in the apical half by P23 (Fig. 5A) and in the basal half by P16 (Fig. 5B) and not detectable (i.e., not significantly different from the $-\mathrm{RT}$ control) at later times. This pattern of post-kanamycin loss of myosin VIIa is consistent with the histological data quantified in Figure 3 and, together with the absence of $\mathrm{ABR}$, indicates that the kanamycin treatment eliminated hair cells in the OCs used for the NTF assays.

Figures 6 and Figures 7 show expression of several factors known to be trophic to SGNs: NT-3, BDNF, GDNF, neurturin, artemin, and CNTF. Of these, NT-3, CNTF, and neurturin are the most abundant based on the qPCR assay. Most of these factors exhibit one of two types of expression patterns. The first type of pattern (Fig. 6) - exemplified by NT-3, CNTF, and GDNF-is characterized by a postnatal increase in expression and a significantly reduced expression level in OCs from kanamycin-treated 


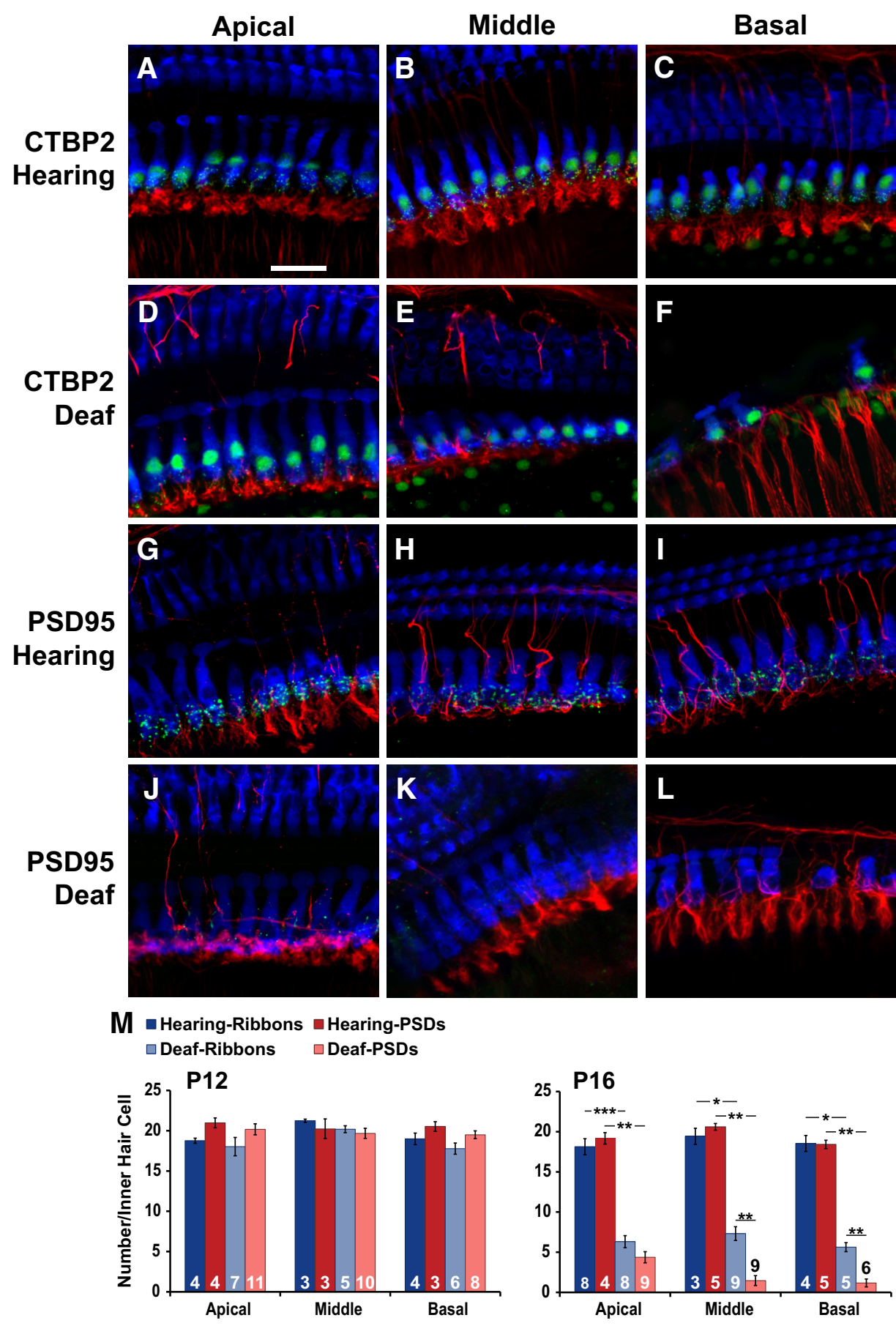

Figure 4. Representative examples of whole-mount preparations taken from hearing and deafened rats and quantification of synaptic structures. As described in Material and Methods, rats were killed at P12 or P16, and their OCS, along with the attached spiral ganglion, were removed. Hair cells were immunolabeled with combined anti-myosin VI and myosin VIla antibodies (blue), SGNs were immunolabeled with chicken NF200 antibody (red), and synaptic structures were immunolabeled with either CTBP2 (ribbons) or PSD-95 (PSDs) antibodies (green). All images are presented as a projection image of a confocal series. $A-C$, Preparations taken from the apical, middle, and basal regions of P16 hearing control cochleae. Presynaptic ribbons are labeled with CTBP2. Scale bar, $20 \mu \mathrm{m} . \mathbf{D}-\boldsymbol{F}$, Preparations taken from the apical, middle, and basal regions of kanamycin-treated P16 cochleae. Presynaptic ribbons are labeled with CTBP2. G-I, Preparations taken from the apical, middle, and basal regions of P16 hearing control cochleae. PSDs are labeled with PSD-95.J-L, Preparations taken from the apical, middle, and basal regions of P16 kanamycin-treated cochleae. PSDs are labeled with PSD-95. M, Quantification of synapse loss after kanamycin treatment. Values are represented as synaptic puncta per hair cell. The number in each column is the number of rats used for the counts. Error bars show SEM. Lines show significant differences (Kruskal-Wallis test, Dunn's post hoc for multiple comparisons, ${ }^{*} p<0.05,{ }^{* *} p<0.01$, ${ }^{* * *} p<0.001$ ). Differences between P12 hearing control and P12 deafened rats are not significant. All differences between P16 hearing control and P16 deafened rats are statistically significant. Differences between P12 and P16 deafened rats are significant at the indicated levels for all turns. Differences between ribbons and PSDs after deafening at P16 are significant at the indicated level in the middle and basal regions but not in the apical region.

rats, implying that expression is either in the hair cells themselves or in supporting cells but the presence of hair cells is required for a high expression level. The second type of pattern (Fig. 7) exemplified by neurturin and artemin-is characterized by a nearly constant level of expression postnatally with no significant reduction after kanamycin treatment, implying constitutive expression in OC supporting cells. As described below, BDNF, GDNF, and artemin are expressed at relatively low levels, and, given a high inter- 
A Apical Myosin VIla

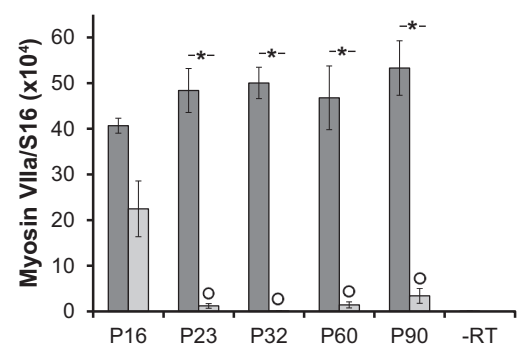

B Basal Myosin VIla

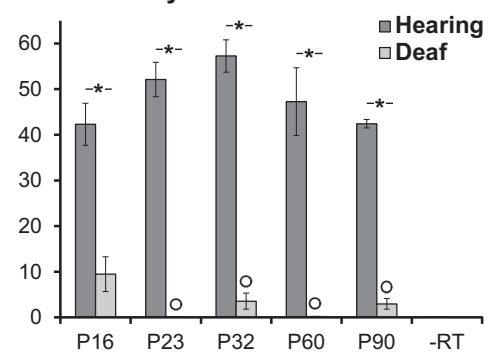

Figure 5. Mean relative myosin VIla expression, normalized to S16, in the apical $(\boldsymbol{A})$ and basal $(\boldsymbol{B})$ halves of the $0 \mathrm{C}$ assayed by qPCR. Error bars show SEM. Myosin VIla declines significantly by P16 and continues to decline to levels not significantly different from - RT (indicated by ${ }^{\circ}$ ) at most time points. Significance was determined by pairwise comparisons by a Mann-Whitney $U$ test. Significant differences are indicated by ${ }^{*} p<0.05 . n=3$ for all columns.

animal variability, it was not possible, for these factors, to establish all aspects of the patterns with statistical significance.

\section{NT-3, CNTF, GDNF, and BDNF expression in the postnatal organ of Corti \\ NT-3}

The NTF NT-3 is crucial to SGN survival during development (Fritzsch et al., 2004) and is expressed postnatally in the OC, with highest levels in IHCs and immediately adjacent supporting cells (Sugawara et al., 2007). Figure 6, $A$ and $B$ shows, respectively, NT-3 transcripts, relative to the S16 reference transcript, in apical and basal portions of rat OCs from control hearing and kanamycin-treated (deaf) rats of various ages from P12 to P90, as well as from $\mathrm{OCs}$ of $\mathrm{P} 0$ and $\mathrm{P} 6$ rats, which are ages before hearing onset and before kanamycin treatment. In control hearing rats, NT-3 transcript levels appear to decline immediately postnatally, falling significantly between P0 and P6, before hearing onset. This implies higher levels of NT-3 expression embryonically, during formation of cochlear innervation than immediately after completion of innervation. Subsequently, at approximately the time of hearing onset - postnatal weeks 2 and 3 (Rübsamen and Lippe, 1998) - NT-3 expression increases in the OC, reaching a plateau by P23-P32, after which time NT-3 expression remains at a constant level at least until P90. The postnatal fall and subsequent rise in NT-3 expression occurs in both apical (Fig. 6A) and basal (Fig. $6 B$ ) portions of the OC. This is shown, for example, by the statistically significant increase in NT-3 mRNA between P12 and P23 in both apical and basal halves of the OC shown in Figure 6, $A$ and $B$.

We also assayed NT-3 mRNA in kanamycin-treated rats from ages P12-P90 (Fig. 6A, B). NT-3 expression in the rat OC does not exhibit the increase with maturation in postnatal weeks 2 and 3 but remains at the prehearing level. For the NT-3 amplification from apical hearing and deaf OCs to match in cycle number, more RNA from the deaf sample had to be used, evident by the reduced number of cycles to amplify the $\$ 16$ reference transcript (Fig. 1A). Thus, relative to S16, less NT-3 RNA is present in the sample from deaf rats than in the sample from hearing rats, indicating a decrease in NT-3 expression after deafening. In kanamycin-treated rats, NT-3 expression in the OC is $<40 \%$ of the control value by P16, the day of the last kanamycin injection. By P23, NT-3 expression in OCs from kanamycin-treated rats is $<30 \%$ of the control value, although still significantly higher than the - RT control. NT-3 expression remains at approximately this level in the OCs of deafened rats at all ages from P16 through P90. Pairwise comparisons show that the expression of NT-3 in control rats is significantly greater than in kanamycintreated (deafened) rats at all time points investigated from P23 to P90 in the apical half (Fig. 6A) and in the basal half (Fig. 6B).

We used a Kruskal-Wallis test (with Dunn's post hoc test) to compare all individual qPCR assays from P23 to P90 among the four groups: (1) hearing-apical; (2) hearingbasal; (3) kanamycin-treated-apical; and (4) kanamycin-treated-basal. This comparison shows a highly significant $(p<0.0001)$ difference between control and kanamycintreated rats in both apical and basal halves.

As shown in Figure 6, $A$ and $B$, by P16 there is a difference, although not significant, in NT-3 expression between hearing and deafened rats, despite the fact that many IHCs remain present at P16. This is particularly striking in the apex (Fig. 6A) in which NT-3 expression is lower in deafened rats although significant loss of IHCs has not yet occurred in the apex at P16 (Fig. $3 D$ ). These data imply that NT-3 expression in the OC is susceptible to ototoxic trauma independently of hair cell death. Although many IHCs remain alive at P16 in kanamycin-treated rats, most synaptic contacts between hair cells and SGNs have already been lost by then, even in the apex (Fig. 4M), raising the possibility that it is the synaptic contacts that are necessary for the increase in NT-3 expression observed in postnatal weeks 2 and 3 .

With respect to temporal pattern (discussed below in detail), NT-3 expression in control and deafened rats diverges by P23 with expression significantly lower in the deaf OC than in the control at P23 and all subsequent time points in both apical and basal halves. That is, after kanamycin treatment and hair cell loss, NT-3 expression in P16-P90 OCs remains at a low neonatal level and does not undergo the increase normally occurring before P23. Continued NT-3 expression in the OC after hair cells are completely absent, i.e., at ages $\mathrm{P} 23$ and older, presumably attributable to a low level of expression by OC supporting cells.

\section{CNTF}

Because CNTF has been shown to exert trophic effects on SGNs (Whitlon et al., 2007), we also assessed expression of CNTF in the OC. Representative examples of amplification curves for CNTF are shown in Figure $1 B$. CNTF mRNA levels in the OC are graphed in Figure 6, $C$ (apical half) and $D$ (basal half). Like NT-3 and neurturin, CNTF is expressed at relatively high levels in the OC and so may also be a significant NTF for SGNs. Like NT-3, CNTF expression significantly declines in postnatal week 1 and then increases in the subsequent 2-3 postnatal weeks.

CNTF expression is reduced in kanamycin-treated rat OCs, but, in contrast to NT-3, CNTF mRNA levels continue to increase during and immediately after kanamycin treatment and only decline after P16. However, there is no significant difference between CNTF expression in deaf and hearing OCs at P16 when most hair cells are still present in the apex and many in the base, nor at P23 when hair cells are absent from the basal and apical OC. Rather, CNTF expression in the OCs of hearing and deafened rats diverges by P60 in the apical half (Fig. 6C) and by P32 in the basal half (Fig. 6D), with expression significantly lower in the deaf OC subsequently. This is later than is the case for NT-3. Pairwise comparisons show significant reduction in CNTF 

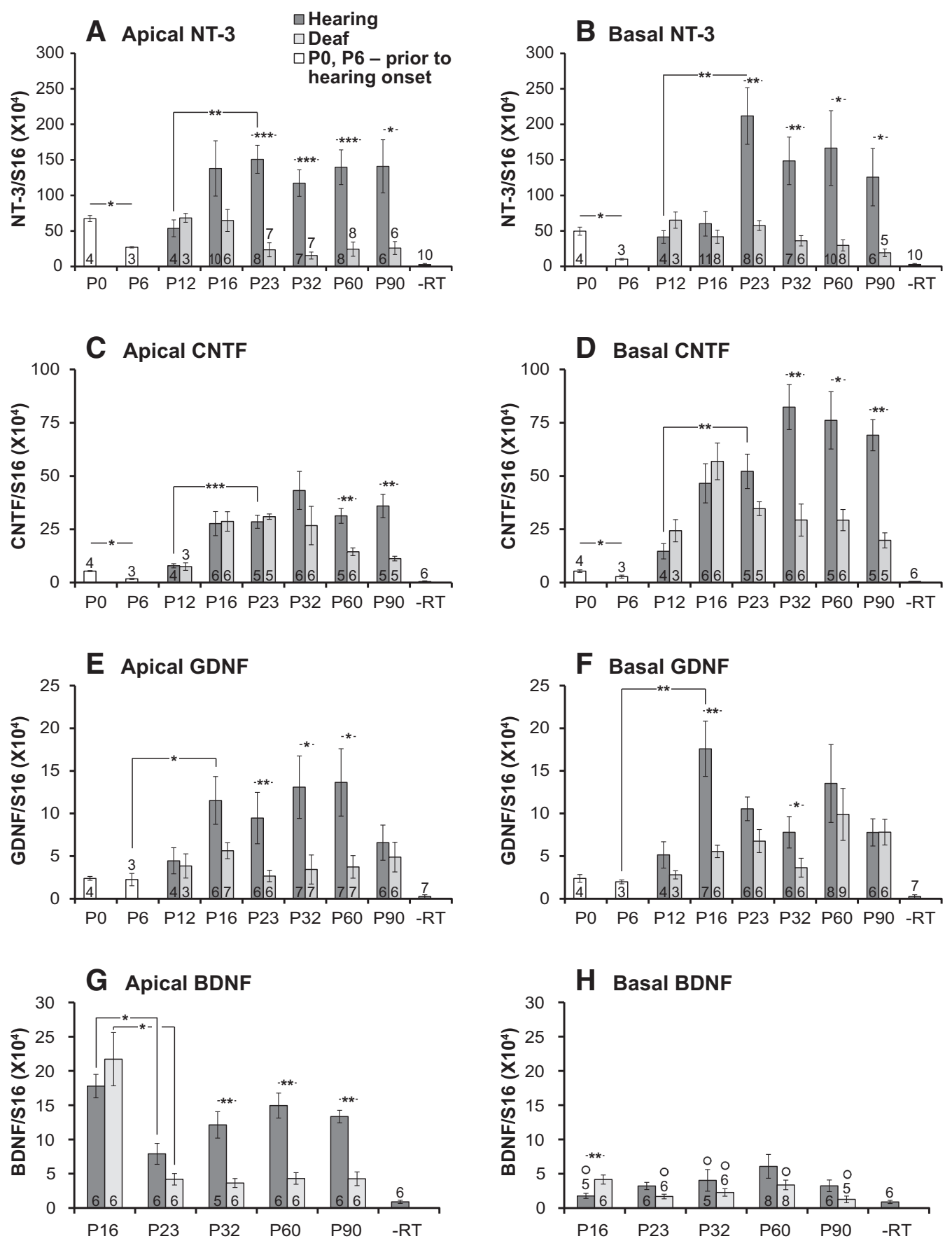

Figure 6. Mean NTF transcript levels, relative to $S 16$, in the apical $(\boldsymbol{A}, \boldsymbol{C}, \boldsymbol{E}, \boldsymbol{G})$ and basal $(\boldsymbol{B}, \boldsymbol{D}, \boldsymbol{F}, \boldsymbol{H})$ halves of the $\mathrm{OC}$, assayed by $\mathrm{qPCR}$. For all of the ages indicated (postnatal days), dark gray columns are data from control (Hearing) rats, light gray columns are data from kanamycin-treated (Deaf) rats, and white columns are data from P0 and P6 rats before initiation of kanamycin treatment and before hearing onset. $\boldsymbol{A}, \boldsymbol{B}, \mathrm{NT}-3 ; \boldsymbol{C}, \boldsymbol{D}, \mathrm{CNTF} ; \boldsymbol{E}, \boldsymbol{F}, \mathrm{GDNF} ; \boldsymbol{G}, \boldsymbol{H}, \mathrm{BDNF}$. Error bars show SEM. Significance was determined for indicated pairwise comparisons by a Mann-Whitney $U$ test and for multiple comparisons by a Kruskal-Wallis/Dunn's post hoc test. Significant differences are indicated by ${ }^{*} p<0.05,{ }^{* *} p<0.01$, and ${ }^{* * *} p<0.001$ for all graphs. Note the difference in $y$-axis scale for these factors. Transcript levels are significantly reduced after deafening at multiple later time points for all of these factors. Values not significantly different from $-\mathrm{RT}$ are indicated by ${ }^{\circ}$.

mRNA in the apical half only at P60 and P90 and in the basal half at P32, P60, and P90. CNTF remains present at near control levels even when NT-3 expression is at a low level. Thus, SGN death begins at a time when $\mathrm{CNTF}$ is still expressed, but the gradually declining CNTF level over the following $\sim 10$ weeks parallels the gradual loss of SGNs in neonatally deafened rats (Alam et al., 2007). That CNTF expression declines during the period in which SGNs die (P23-P90; Alam et al., 2007) suggests that SGN death may be, at least in part, attributable to loss of trophic support by CNTF.
To confirm the reduced CNTF levels in kanamycin-treated relative to hearing control OCs after P32, we used a KruskalWallis test (with Dunn's post hoc test) to compare all individual qPCR assays from P32 to P90 among the four groups: (1) hearing-apical; (2) hearing-basal; (3) kanamycin-treated-apical; and (4) kanamycin-treated-basal. This comparison shows a significant difference between kanamycin-treated and control for the apical half $(p=0.0033)$ and for the basal half $(p<0.0001)$. This test also shows that CNTF expression is significantly higher in the basal half than in the apical half of the OC $(p=0.026)$. This raises 

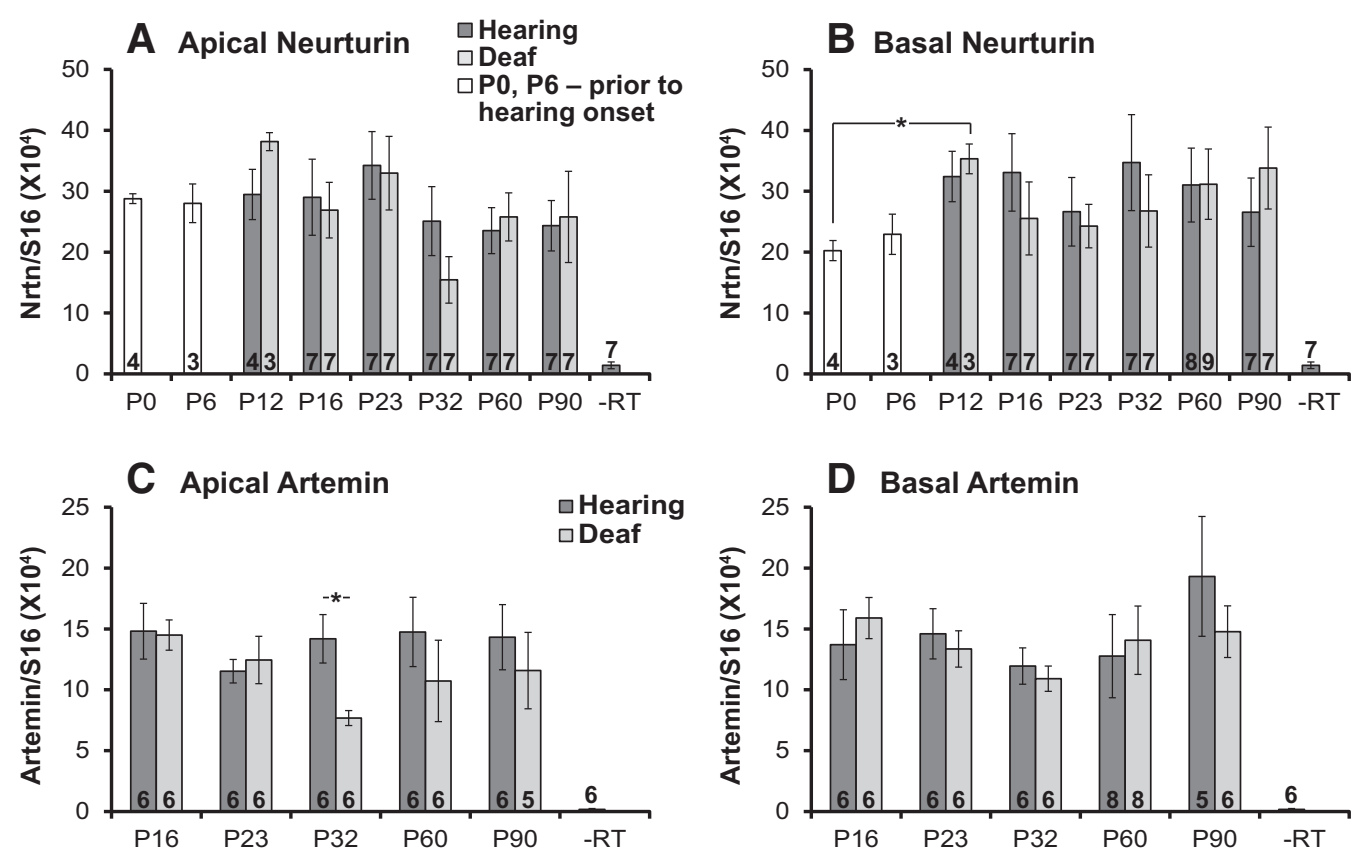

Figure 7. Mean NTF transcript levels, relative to $S 16$, in the apical $(\boldsymbol{A}, \boldsymbol{C})$ and basal $(\boldsymbol{B}, \boldsymbol{D})$ halves of the $\mathrm{OC}$, assayed by $q \mathrm{PCR}$. For all of the ages indicated (postnatal days), dark gray columns are data from control (Hearing) rats, light gray columns are data from kanamycin-treated (Deaf) rats, and white columns are data from P0 and P6 rats before initiation of kanamycin treatment and before hearing onset. $\boldsymbol{A}, \boldsymbol{B}$, Neurturin; $\boldsymbol{C}, \boldsymbol{D}$, artemin. Error bars show SEM. Significance was tested for all pairwise comparisons of hearing versus deaf at each age (Mann-Whitney $U$ test) and for multiple comparisons across time points (Kruskal-Wallis/Dunn's post hoc test). Significant differences are indicated by ${ }^{*} p<0.05$.

the possibility that CNTF, like BDNF and NT-3 (Adamson et al., 2002; Flores-Otero et al., 2007; Green et al., 2012), participates in inducing differences in physiological properties between apical and basal SGNs.

\section{GDNF}

GFLs-GDNF, neurturin, and artemin (Airaksinen and Saarma, 2002) - are expressed in the cochlea (Stöver et al., 2000) and have been shown to be capable of providing trophic support to SGNs (Ylikoski et al., 1998; Yagi et al., 2000; Warnecke et al., 2010), so we next assessed expression of GFLs in the OC. Representative examples of amplification curves for GDNF are shown in Figure $1 C$. GDNF is expressed in the rat $\mathrm{OC}$ in hearing and deaf rats but at relatively low levels relative to NT-3 and CNTF. For example, the midpoint of the NT-3 amplification curve (Fig. $1 A$ ) is at 32.2 cycles, and the midpoint of the GDNF amplification curve (Fig. $1 C)$ is at 37.8 cycles. The difference of 5.6 cycles corresponds to a 48.5-fold difference in transcript levels between NT-3 and GDNF. Moreover, 40 cycles is the detection limit on the Roche Lightcycler 480 used for these assays, so cycle numbers near 40, such as those we obtained for GDNF, are near the level of detectability for this assay. Nevertheless, GDNF transcript levels are significantly different from the $-\mathrm{RT}$ control at all time points (Fig. 6E,F), indicating that GDNF is expressed at a significant level above background and can act as an NTF for SGNs in vivo.

GDNF mRNA levels in the OC are shown in Figure 6, $E$ (apical half) and $F$ (basal half). In contrast to NT-3 and CNTF, the level of GDNF transcript does not decline in postnatal week 1 . Nevertheless, like NT-3 and CNTF, there appears to be an increase in GDNF expression concomitant with hearing onset. There was no apparent significant difference in expression level between apical and basal halves.

As with NT-3 and CNTF, GDNF mRNA expression is reduced in kanamycin-treated OCs. Pairwise comparisons show significant reduction in the apical half at P23, P32, and P60 (Fig. 6E) and in the basal half at P16 and P32 (Fig. 6F) but not at later times assayed. This indicates that, as is the case for CNTF, surviving supporting cells in the OC continue to produce GDNF in the absence of hair cells. GDNF, although possibly at a low level, is available to SGNs from the OC even at a time when they are dying.

\section{$B D N F$}

Representative examples of amplification curves for apical BDNF are shown in Figure $1 D$. BDNF, like GDNF, appears to be expressed at low levels, relative to NT-3 and CNTF, in the OC at all ages and conditions. For example, the midpoint of the BDNF amplification curve (Fig. 6A) is at 38.4 cycles, corresponding to a 73.5-fold difference in the amount of transcript relative to NT-3. Although close to the detection limit, this is still significantly above background and consistent with a possibility that BDNF can act as an NTF for SGNs, at least in the apex. Comparison of all BDNF qPCR assay data from apical and basal OC from control and deafened rats at P23-P60 shows that the BDNF mRNA level in the apical half is significantly greater than in the basal half in control hearing rats $(p<0.0001$, Kruskal-Wallis test, Dunn's post hoc test). BDNF mRNA levels in the OCs are shown in Figure 6, $G$ (apical half) and $H$ (basal half). BDNF expression is highest at the earliest time assayed, P16, and then declines significantly by P23 in the apex. Assay of BDNF mRNA in the basal half shows a low level of transcripts relative to the $-\mathrm{RT}$ control, at some time points not significantly different from the $-\mathrm{RT}$ control (Fig. $6 H)$. Thus, both BDNF and CNTF exhibit variation in expression along the apex-base axis but in opposing orientations, with BDNF higher in the apex than in the base and CNTF higher in the base than in the apex.

As shown in Figure $6 G$, there is no significant difference in BDNF expression between deafened and hearing OCs at P16 in the apical half when most hair cells are still present, nor at P23 when all hair cells, including IHCs, are absent. This suggests that surviving supporting cells in the OC continue to produce BDNF, 
albeit at a low level, for a period of time after hair cells are absent. In the apical half, a significant decline in BDNF expression after kanamycin treatment can be detected at ages older than P23, the period in which most SGNs are lost. This is evident in pairwise comparisons at P32, P60, and P90, which show statistically significant differences between control hearing and deafened rats. Moreover, the Kruskal-Wallis test referred to in the preceding paragraph shows a significant $(p=0.0002)$ difference between BDNF transcript levels in the apical halves of control hearing and deafened OCs. In the basal halves, the same test shows no significant difference between hearing and kanamycin exposed OCs. However, even in control hearing rats, BDNF levels are very low in the basal half of the OC, so any decrease would be difficult to detect.

In summary, NT-3, CNTF, GDNF, and BDNF exhibit expression patterns in the OC marked by an inhibition of the normal postnatal increase in expression after kanamycin exposure, an inhibition that is very rapid in the case of NT-3, and, at least for the first three, a postnatal increase in expression approximately concomitant with hearing onset. Also, CNTF and BDNF show a clear spatial pattern of expression in mature normal hearing rats, with CNTF higher in the basal half of the OC and BDNF higher in the apical half.

\section{Neurturin and artemin expression in the postnatal OC}

Two GFLs other than GDNF, neurturin and artemin, are expressed in the OC. They exhibit patterns of expression very different from those of NT-3, CNTF, GDNF, and BDNF in that their expression levels are nearly constant postnatally, even after deafening, and are similar in apical and basal halves.

Representative examples of amplification curves for neurturin are shown in Figure $1 E$ and for artemin in $F$. The midpoint of the neurturin amplification curve is at 35.5 cycles, corresponding to a 9.6-fold lower transcript level than NT-3. The midpoint of the artemin amplification curve is at 36.9 cycles, corresponding to $\sim 26$-fold lower transcript level than NT-3. Nevertheless, both neurturin and artemin levels are significantly greater than the - RT control so they can provide neurotrophic support to SGNs. Neurturin is expressed at higher levels than is BDNF, GDNF, or artemin. Neurturin mRNA levels in the $\mathrm{OC}$ are shown in Figure $7 A$ (apical half) and $B$ (basal half), and artemin in $C$ (apical half) and $D$ (basal half). As noted above, for both factors, expression is comparable at all time points in hearing and deafened rats and in both locations. Neurturin and artemin expression in the OC continues unchanged after deafening at least through P90, by which time few SGNs remain. Thus, neurturin and artemin are available to SGNs as potential NTFs after loss of hair cells, despite the fact that SGNs are dying.

\section{The temporal pattern of postnatal NTF expression in the OC} Representative time courses of NTF expression are shown in Figure 8, the apical half in $A, C$, and $E$, and the basal half in $B, D$, and $F$. These data are replotted from Figures 6 and Figures 7. NT-3, $\mathrm{CNTF}$, and neurturin expression time courses were chosen because these clearly exemplify the two categories of expression patterns observed here: (1) postnatal increase in expression with failure of this increase to occur or to be sustained in deafened rats; and (2) relatively stable expression throughout the postnatal period, apparently unaffected by deafening. NT-3 and CNTF exemplify the first type of pattern and neurturin the second. These three were chosen as representative because, among the NTFs we assayed, they are expressed at the highest levels, which facilitates definitive quantitation and implies that they may be the most significant for support of SGN survival. With regard to the other
NTFs assayed, BDNF and GDNF share the same expression pattern as NT-3 and CNTF, although at a lower level of expression; artemin shares the same pattern as neurturin, although at a lower level of expression.

For NT-3 and CNTF, there is an immediate postnatal decline in expression, followed by an increase approximately concomitant with hearing onset. The statistical analysis shown in Figure 6 establishes these changes as significant. In Figure 8, they are depicted graphically on a timescale from P0-P90. To simplify the figure, the statistical information-error bars and comparisons - shown in Figures 6 and 7 and discussed above are not also included in Figure 8. For control hearing rats, the P0-P90 timescale is divided into three parts, defined by the key postnatal physiological event in the rat auditory system: hearing onset. This is the period from early in postnatal week 2 through the end of postnatal week 3 , over which hearing begins and hearing threshold gradually falls to the mature level. Because this study is primarily concerned with expression in the mature auditory system and the consequences of deafening, expression before hearing onset was assayed only to determine a baseline level. NTF expression and its role in inner ear development have been described previously (Fritzsch et al., 2004). In that regard, it should be noted that the earliest time at which we assayed, P0, does not mark a notable event in inner ear development, which begins before birth and is not complete until several days after birth in the rodent (Rübsamen and Lippe, 1998). P0 is the earliest time point before hearing onset at which inner ear tissue is readily accessible.

Because of our focus on NTF expression during and after hearing onset, the timescale is divided into three parts on that basis: (1) P6-P23, from just before to just after the period of hearing onset; (2) P0-P6, before hearing onset; and (3) P23-P90, mature hearing. For illustrative purposes, in each of these divisions, NT-3 (Fig. $8 A, B$ ) or CNTF expression (Fig. $8 C, D$ ) as a function of time in control hearing rats is represented by a trend line determined by a linear regression analysis of NTF expression at the time points included in the division. The lines show the decrease in expression at $\mathrm{P} 0-\mathrm{P} 6$, the increase at $\mathrm{P} 6-\mathrm{P} 23$, and the stable level at P23-P90 for NT-3 and CNTF in the apical and basal halves of the OC. Although not necessary to establish statistical significance of the changes in expression level, these trend lines are consistent with the analyses and statistical significance shown in Figure 6. For normal hearing rats, the trend lines from P0 to P6 in Figure $8 A-D$ show a statistically significant negative slope in the apical and basal halves of the OC for both NT-3 (apical, $p=$ 0.0005; basal, $p=0.0022$ ) and CNTF (apical, $p<0.0001$; basal, $p=0.0353$ ). The trend lines from $\mathrm{P} 6$ to $\mathrm{P} 23$ in Figure $8 A-D$ show a statistically significant positive slope from P6 to P23 in the apical and basal halves of the OC for both NT-3 (apical, $p=$ 0.0261; basal, $p=0.0001$ ) and CNTF (apical, $p=0.0018$; basal, $p=0.0002$ ). From $\mathrm{P} 23$ to $\mathrm{P} 90$, all trend lines for hearing rats have slopes not significantly different from zero for CNTF and NT-3, both apical and basal halves.

Again, for illustrative purposes, trend lines (dashed lines) for NT-3 and CNTF expression in deafened rats are drawn from P16 through P90, with P16 being the end of the period of kanamycin injection and a time at which IHC death is clearly underway (Fig. 3 ). As shown in Figure 6, $A$ and $B$, and described in the accompanying text, expression of NT-3 is significantly lower in OCs of deafened relative to hearing control rats $\mathrm{P} 23$ and older. This is illustrated in Figure 8, $A$ and $B$, by the dashed trend lines from P16 to P90 that allow graphic comparison of NT-3 expression between hearing and deafened rats. The slopes of these trend lines are not significantly different from zero in Figure 8, in either $A$ or 

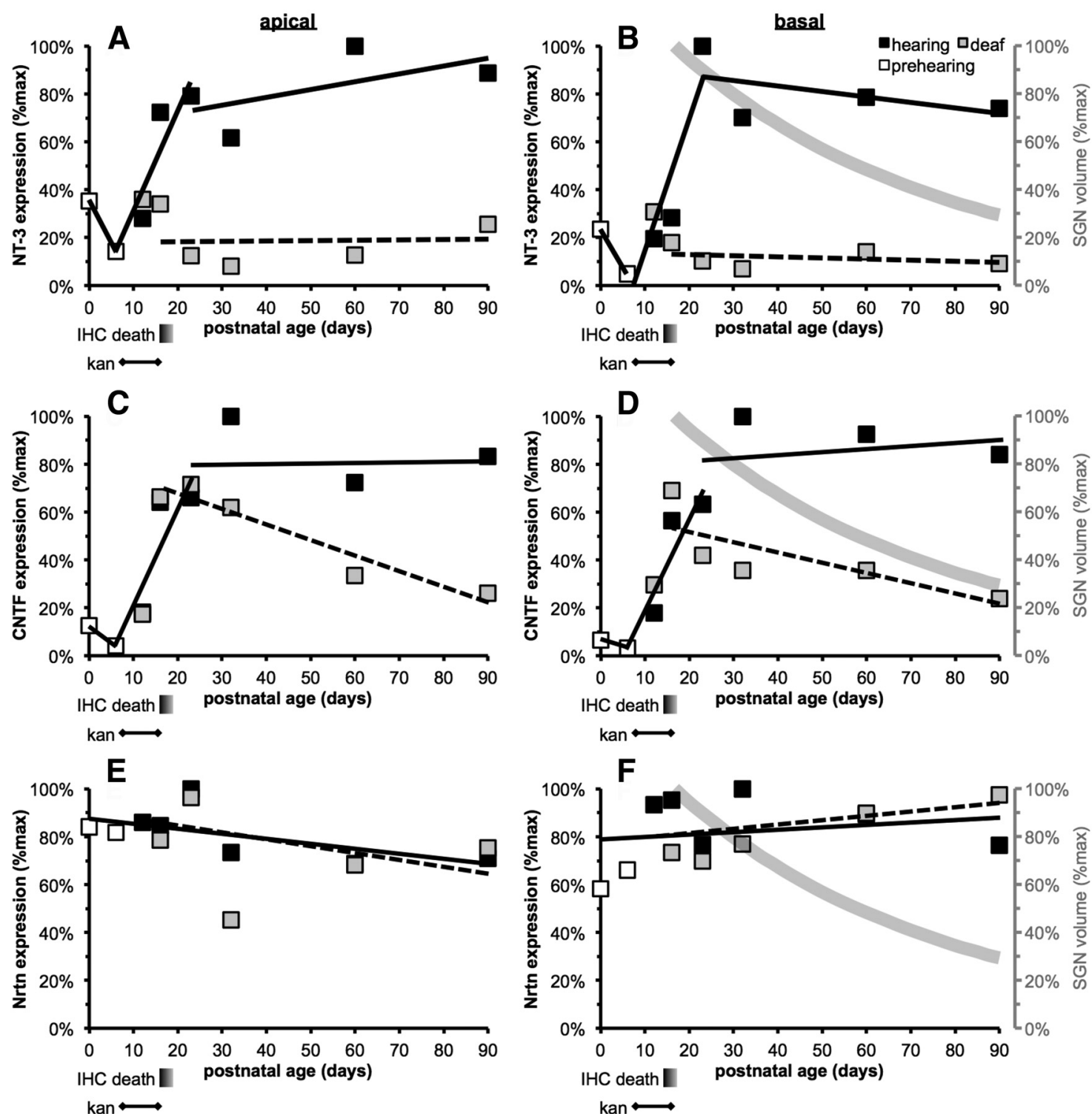

Figure 8. Temporal expression pattern for representative NTFs. Data from Figures $6(\boldsymbol{A}-\boldsymbol{D}$ here) and 7 ( $\boldsymbol{E}, \boldsymbol{F}$ here) are replotted to better show expression of NT-3 $(\boldsymbol{A}, \boldsymbol{B}), \mathrm{CNTF}(\boldsymbol{C}, \boldsymbol{D})$, and neurturin $($ Nrtn; $\boldsymbol{E}, \boldsymbol{F})$ in hearing (filled squares) and deafened (open squares) rats, as a function of postnatal age, in the apical $(\boldsymbol{A}, \boldsymbol{C}, \boldsymbol{E})$ and basal $(\boldsymbol{B}, \boldsymbol{D}, \boldsymbol{F})$ halves of the $0 C$. The horizontal axis shows postnatal age in days, to scale. Below this axis are shown the approximate period over which IHCs die in the apex and base (from Figs. 2,3), depicted as a shaded bar, and the period over which kanamycin (kan) is administered. For illustrative purposes, expression trends over time are indicated on the graphs by heavy black lines, solid for hearing rats, and dashed for deaf rats. For control hearing rats, trends in NT-3 and CNTF expression are shown separately for three time periods: (1) immediately postnatally, expression declines, illustrated by the line from P0 to P6; (2) during hearing onset, expression increases, illustrated by a best-fit line computed by linear regression from P6 to P23; and (3) after hearing onset, expression is stable, illustrated by a best-fit line computed by linear regression from P23 to P90. For deafened rats, trends are illustrated differently for NT-3 and CNTF expression. For NT-3, the trend is illustrated by a best-fit line computed by linear regression from P12 to P90 and, for CNTF, by a line connecting P12 to P16 and a best-fit line computed by linear regression from P23 to P90. The trends in neurturin expression for hearing and deafened rats are separately illustrated by best-fit lines computed by linear regression from P23 to P90. The gray curve in $\boldsymbol{B}, \boldsymbol{D}$, and $\boldsymbol{F}$ approximates the loss of SGNs in the cochlear base over the time period of these experiments based on data published by Alam et al. (2007).

$B$, confirming what was shown in Figure 6, that deafening prevents the postnatal upregulation of NT-3 expression from as early as we can define an effect of deafening.

Because of the nonlinearity of expression as a function of time, a linear regression analysis is not the optimal choice to compare overall expression trends between hearing and deafened rats. Instead, a generalized regression model (GRM) was used to compare expression from P0 to P90 between hearing and deafened rats. The GRM analysis shows that the temporal patterns are significantly different for both NT-3 (apical, $p=0.0008$; basal, $p=0.0257$ ) and CNTF (apical, $p=0.0001$; basal, $p<0.0001$ ).

Although CNTF expression, like that of NT-3, is lower in the
OCs of deafened rats relative to control, the temporal pattern of CNTF expression differs from that of NT-3. As shown in Figure 6, $C$ and $D$, and described in the accompanying text, expression of CNTF is not significantly lower in deafened relative to hearing control rats at P23, as is the case for NT-3. Rather, CNTF expression in deafened rats is not significantly lower than expression in hearing rats until P23-P32 in the basal OC nor until P32-P60 in the apical OC. Thus, CNTF expression does increase in the OCs of deafened rats at the same time as it would have occurred in control rats-at the time of hearing onset- despite the fact that the kanamycin-treated rats did not experience an onset of hearing. After this initial increase, CNTF expression gradually de- 
clines in the deafened rat OC. This is illustrated by the dashed trend lines in Figure 8, $C$ and $D$, which have significantly negative slopes (apical, $p=0.0007$; basal, $p=0.0048$ ). These data indicate that hearing is not necessary for the postnatal increase in CNTF but may be for NT-3. Nevertheless, for both factors, expression is not maintained after deafening.

Expression of neurturin (Fig. 8E,F) represents a pattern of expression different from that of NT-3 or CNTF. Neurturin is expressed at a relatively constant level from P0 through P90 in both the apical (Fig. 8E) and basal (Fig. 8F) halves. This is illustrated by trend lines (solid) calculated by linear regression, for which the slopes are not significantly different from zero for both apical and basal halves. Moreover, neurturin expression does not change significantly after treatment with kanamycin (Fig. $7 A, B$ ). In Figure $8, E$ and $F$, this is illustrated by dashed trend lines for which, again, the slopes are not significantly different from zero. Comparison of the trend lines in Figure 8, $E$ and $F$, shows no significant difference between hearing and deaf by linear regression or by using a GRM.

Figure $8, B, D$, and $F$, graphically relates NTF expression to SGN survival. The gradual loss of SGNs (light gray curve) in the basal cochlea is abstracted from Alam et al. (2007). This trend line is an exponential fit to SGN volume measurements presented in that study. It is superimposed over the NTF expression in the basal OC in Figure 8, B, D, and $F$. Superimposing these trend lines shows that SGN loss begins while CNTF and neurturin expression are still present in the OC. Although this might be taken to imply that NT-3 is solely necessary for SGN survival, it should be noted that all SGNs remain alive for several weeks even when NT-3 expression is low, and many are alive more than 2 months later.

\section{NTF expression in the OC after deafening adult rats}

Among the NTFs that we assayed, NT-3 appears unique in that its expression is low in rats immediately after deafening, suggesting that its expression is dependent on hair cell viability or the presence of synapses. The neonatal deafening experiments show that the maturational increase in NT-3 expression does not occur in the absence of hair cells. We next asked whether loss of hair cells would result in decreased NT-3 expression in the adult when NT-3 expression is already at its maximal level. To do so, we deafened adult rats with gentamicin/furosemide injections and assayed expression of NT-3 and CNTF by qPCR in the OC (Fig. 9).

To verify hair cell loss using this protocol, rats were killed 2 weeks after treatment with gentamicin and furosemide. From one cochlea in each rat, we removed the OCs with the spiral ganglion attached and immunolabeled the hair cells and the SGNs as described in Materials and Methods. As shown in Figure $9 A-C$, this protocol effectively eliminated hair cells when compared with an age-matched normal hearing control rat (Fig. 9D). As observed in neonatally deafened rats, many SGN peripheral axons continue to extend to the OC even after hair cells have been lost (Fig. 9A-C).

Relative expression of NT-3 and CNTF in adult deafened OCs was assayed using qPCR (Fig. 9E). Five to seven separate repetitions were done, with each repetition containing one OC from each adult rat (the other being used for immunohistochemical labeling of hair cells). Results are presented as expression levels (normalized to S16), and the ratio of expression between deaf and hearing is also shown. Two weeks after treatment with gentamicin/furosemide, expression of NT-3 decreases significantly in the OC when compared with age-matched hearing control rats, implying that NT-3 expression in the mature OC requires hair cells.
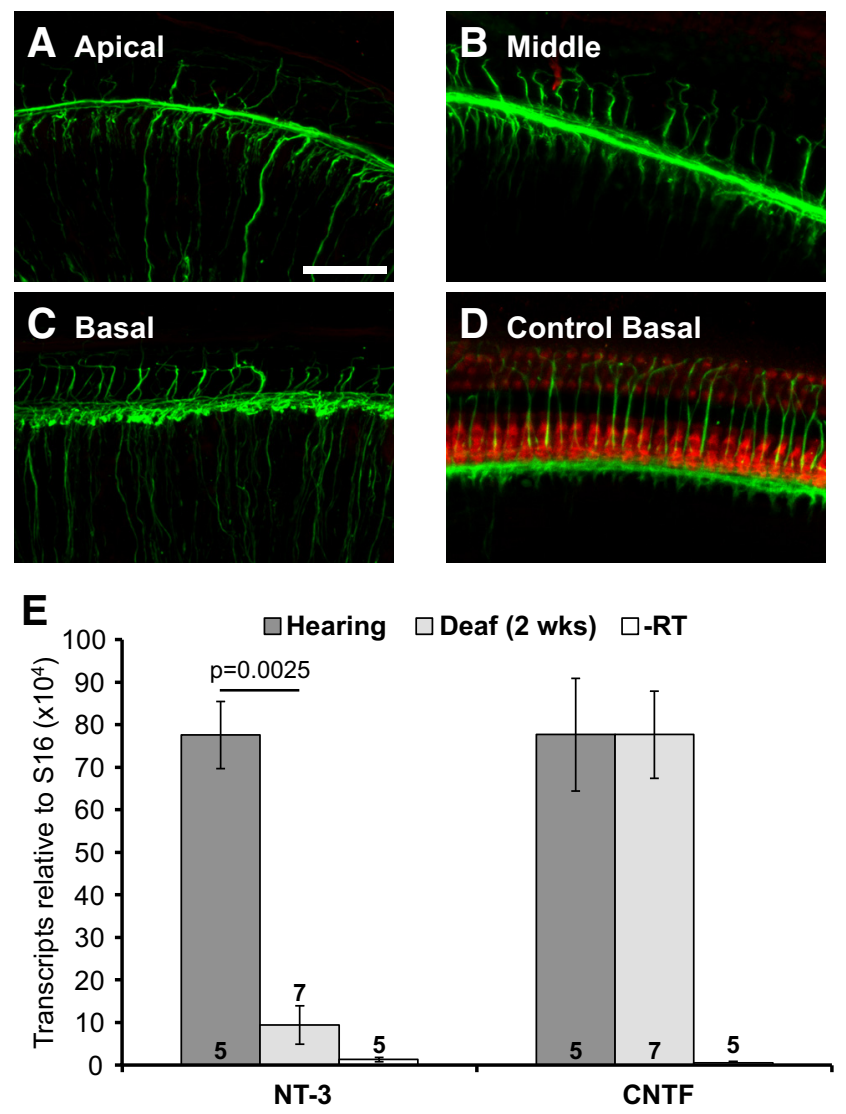

Figure 9. NT-3 and CNTF expression in rats deafened as adults. $\boldsymbol{A}-\boldsymbol{D}$, Representative examples of 0 Cs from adult deafened and control hearing rats 2 weeks after gentamicin/furosemide injections showing hair cells and their innervation. As described in Materials and Methods, portions of the $\mathrm{OCS}$, with spiral ganglion attached, were removed and immunolabeled with combined rabbit anti-myosin VI and anti-myosin VIla (red) antibodies, and SGNs were immunolabeled with mouse anti-neuronal mix (green). Shown are z-projections of confocal microscope z-stacks of entire whole mounts. Scale bar, $50 \mu \mathrm{m}$. $\boldsymbol{A}-\boldsymbol{C}$, Deafened rat cochlear apical region $(\boldsymbol{A})$, middle region $(\boldsymbol{B})$, and basal region $(\boldsymbol{C})$. $\boldsymbol{D}$, Basal region from control undeafened rat. $\boldsymbol{E}$, Mean NT-3 and CNTF expression normalized to $S 16$ in the $0 C$, assayed by $q P C R, 2$ weeks after gentamicin/furosemide injections and in control hearing rats. Error bar shows SEM. The number in each column is the number of biological replicates. As shown, NT-3 expression is significantly lower after deafening relative to the hearing control (Mann-Whitney $U$ test).

In contrast, no decline in CNTF expression could be detected 2 weeks after gentamicin/furosemide. As in neonatally deafened rats, CNTF continues to be expressed after loss of hair cells, presumably in surviving OC supporting cells.

\section{NTF expression in the cochlear nucleus}

NTF expression levels were determined in the cochlear nucleus using qPCR. The NTFs NT-3, BDNF, GDNF, and artemin (Fig. $10 A-D)$ are expressed at low levels in the cochlear nucleus; for BDNF, GDNF, and artemin at levels not significantly different from the $-\mathrm{RT}$ condition for most or all time points. However, neurturin and CNTF (Fig. 10E,F) are expressed in the cochlear nucleus at significant levels at all ages. This confirms previous detection, by immunoblot and immunohistochemistry, of CNTF in the cochlear nucleus (Hafidi et al., 2004). These results imply that, of the NTFs assayed, CNTF and neurturin are the ones most likely to be the principal postsynaptic target-derived NTFs for SGNs. Expression of CNTF and neurturin is maintained without significant decline after loss of hair cells. Thus, these two factors are available to SGNs from both presynaptic and postsynaptic sources throughout the time that SGNs are dying after hair cell loss. 

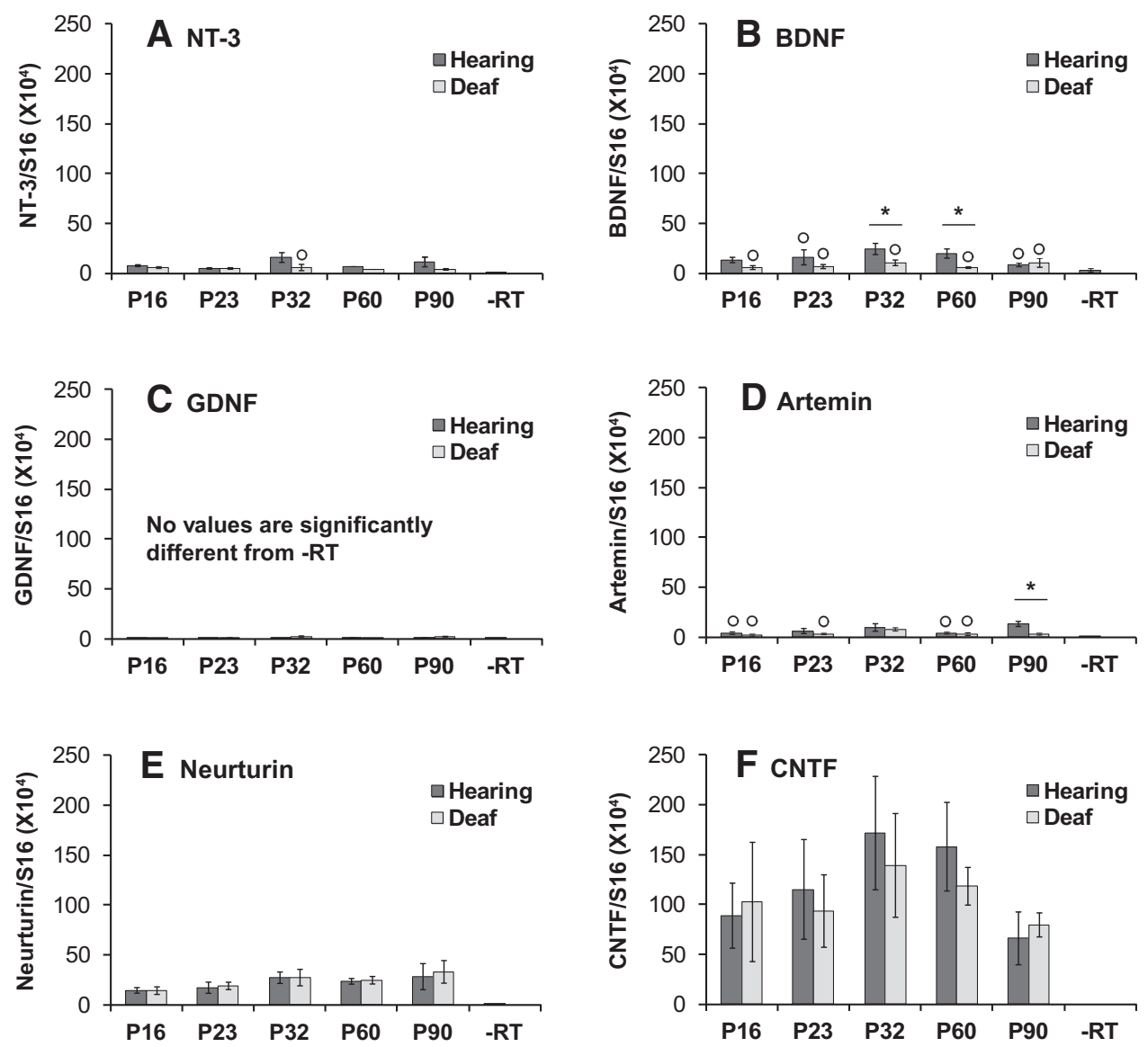

Figure 10. Expression of NTFs in the cochlear nucleus. $\boldsymbol{A}, \mathrm{NT}-3 ; \boldsymbol{B}, \mathrm{BDNF} ; \boldsymbol{C}, \mathrm{GDNF} ; \boldsymbol{D}$, artemin; $\boldsymbol{E}$, neurturin; $\boldsymbol{F}$, CNTF. Expression of NT-3, BDNF, GDNF, and artemin is very low. Error bars show SEM. Values not significantly different from the $-\mathrm{RT}$ control are indicated by ${ }^{\circ}$. Significant differences between hearing and deaf rats at particular time points are indicated by ${ }^{*} p<0.05$ (Mann-Whitney $U$ test). $n=4$ for NT-3 and BDNF; $n=3$ for GDNF, artemin, neurturin, and CNTF.

\section{Discussion}

A commonly used animal model for studying deafness is that in which hair cells are destroyed by aminoglycoside exposure (Spoendlin, 1975). In this model, SGNs survive for many weeks after loss of hair cells. After neonatal aminoglycoside exposure in rats, loss of $\sim 90 \%$ of the SGNs occurs gradually over $\sim 3$ months, with $\sim 10 \%$ of the neurons surviving for at least $150 \mathrm{~d}$ after kanamycin treatment (Alam et al., 2007). Bichler et al. (1983), using a similar deafening protocol in rats, found that $\sim 90 \%$ of the SGNs were lost gradually over 12 months, with the remaining $\sim 10 \%$ surviving for at least 21 months. To understand how it is possible for SGNs to survive without hair cells, we asked whether NTFs are available to SGNs from presynaptic or postsynaptic target regions in adult hearing and deafened rats.

\section{Cellular changes after neonatal aminoglycoside exposure}

Previous studies have reported damage to synaptic structures after aminoglycoside exposure (Dodson, 1997; Lenoir et al., 1999). Lenoir et al. (1999) provided evidence from electron microscopy that synapse loss precedes loss of IHCs in aminoglycoside-treated rats. Here, we show quantitatively that, by P16, nearly all PSDs have disappeared from the base of the IHCs. Most IHCs are lost between P16 and P18. Loss of PSDs tends to precede loss of presynaptic ribbons, suggesting that PSDs are more susceptible to ototoxic trauma than are presynaptic ribbons and IHCs.
The immediate consequences of aminoglycoside exposure to IHC synapses (Dodson, 1997) resemble those of excitotoxic trauma in vivo (Pujol et al., 1985; Puel et al., 1991, 1998) or in vitro (Wang and Green, 2011): swelling and rapid degeneration of the postsynaptic bouton even while the hair cells remain intact. Noise trauma can cause a similar "synaptopathy" (Puel et al., 1998; Kujawa and Liberman, 2006, 2009) via excitotoxicity (Puel et al., 1998), followed by a gradual loss of SGNs (Kujawa and Liberman, 2006, 2009). It is tempting to speculate that the gradual loss of SGNs after aminoglycoside exposure is likewise related to the preceding synaptopathy.

\section{Expression of some NTFs is reduced after deafening}

NT-3 expression is declining neonatally until approximately the time of hearing onset. NT-3 expression then increases significantly in the OC, reaching a plateau by P23, sustained until at least P90. The increase in NT-3 expression at approximately the time of hearing onset may be required for reasons other than SGN survival. For example, NT-3 may play a role in potentiating hair cell excitability (Kimitsuki et al., 2003).

After neonatal kanamycin treatment, the maturational NT-3 increase fails to occur, and after adult deafening, NT-3 expression rapidly declines, implying that hair cells account for most NT-3. Studies show NT-3 expression in OC supporting cells (Pirvola et al., 1992; Ylikoski et al., 1993; Schecterson and Bothwell, 1994; Sugawara et al., 2005, 2007), but this may be only a small fraction 
of the total. Alternatively, much NT-3 may be produced in the supporting cells but requiring the presence of intact hair cells. Perhaps hair cell loss initiates changes in supporting cells that reduce their expression of NTFs, even before the supporting cells convert to a flattened epithelium. Notably, there is significantly lower NT-3 expression in kanamycin-treated OCs even when many hair cells are still present- especially evident in the apexsuggesting that NT-3 expression depends not just on presence of hair cells but on their functional integrity and, possibly, on maintained synaptic contact with the SGNs.

Although NT-3 is crucial to SGN survival during cochlear development (Fritzsch et al., 2004), SGN survival after deafening is likely attributable to NTFs other than NT-3, given that levels of NT-3 in the OCs of deafened rats are much lower than in the OCs of normal hearing rats. CNTF expression, like that of NT-3, declines immediately after birth, increases at approximately the time of hearing onset, and declines after deafening. In general, factors that show a postnatal increase in expression are those that show a decrease after deafening, suggesting that hair cell function plays a role in promoting expression of these NTFs. In contrast to NT-3, hair cells are no longer present well before there is a significant reduction in CNTF expression after kanamycin, implying CNTF expression in supporting cells. CNTF expression is initially present but then declines during the period in which SGNs die (P23-P90; Alam et al., 2007). Nevertheless, many SGNs are lost while CNTF expression is still high.

Why does expression of some NTFs decrease after deafening? One possibility is that conversion of the cytoarchitecturally elaborate sensory epithelium to a simple "flat" epithelium after hair cell loss involves degeneration of supporting cells so that they no longer produce NTFs. However, NTF expression is evidently lower before this conversion in rodents. In mice, the conversion process is not underway until weeks (C57BL/6 mice) to months (CBA/Ca mice) after hair cell death (Taylor et al., 2012). In neonatally deafened rats, Bichler et al. (1983) found surviving supporting cells 6 months after deafening, especially in the apical turns. In contrast, NTF expression declines significantly within 2-3 weeks after hair cell death. Moreover, because there are few surviving SGNs at a time when most supporting cells are still present (Bichler et al., 1983), the presence of supporting cells appears insufficient to maintain SGN survival.

\section{Persistent expression of some NTFs after hair cell death}

Neurturin and artemin remain expressed at approximately the same level from P0 to P90 regardless of maturation or deafening, independent of hair cell function or presence. It has been suggested that OC supporting cells are important for SGN survival (Zilberstein et al., 2012) and may play a role in trophic support of SGNs after hair cell loss (Sugawara et al., 2005). Consistent with this, neurturin and artemin are present after hair cell loss. CNTF continues to be expressed in the cochlear nucleus, the central target of the SGNs, after deafening. BDNF and NT-3 are expressed in neurons and glia of the spiral ganglion (Hansen et al., 2001; Zha et al., 2001). Gene expression profiling studies of spiral ganglion (E. M. Bailey, J. R. Manak, and S. H. Green, unpublished observations) indicate that BDNF, NT-3, and CNTF expression persists in the spiral ganglion after deafening at least through P60. Thus, NTFs are available to SGNs from multiple sources even after hair cell death.

Maintained expression of NTFs in the cochlear nucleus after hair cell loss helps explain observations that auditory nerve central synapses in the cochlear nucleus are maintained in hearing- impaired animals, albeit with morphological changes (O'Neil et al., 2011). Similarly, maintained expression of NTFs in the OC after hair cell loss can explain the persistence of peripheral processes projecting to the OC after aminoglycoside treatment. This is evident, for example, in Figure 2. In cat cochleae examined months after aminoglycoside treatment when fewer than half of the SGNs in the cochlea still survive, the ratio of surviving peripheral axons/surviving neuronal somata in the cochlea is $43 \%$ of normal (Leake et al., 2013). Thus, even at a time when SGNs are dying, nearly half still have axons in the OC.

The observation that expression of some NTFs is maintained after kanamycin exposure helps explain why SGNs persist for so long in the absence of hair cells. Nevertheless, SGNs do eventually die after hair cell loss in some circumstances. Although it is possible that this is attributable to NTF deprivation, it is plausible that there is an as-yet-unidentified cause of SGN death that should be a target of future investigation.

\section{NTFs as therapeutics}

Sensorineural deafness is generally attributable to loss of hair cells and can be ameliorated through the use of cochlear implants that electrically stimulate SGNs. Prevention of SGN degeneration should improve the efficacy of cochlear implants, and treatment with NTFs has been proposed as a means of accomplishing this (Shibata et al., 2011). We suggest that SGNs are not entirely deprived of NTFs after deafening and not necessarily dying because of lack of NTFs. Nevertheless, intracochlear delivery of NTFs, typically at high concentrations, does reduce SGN death after deafening (Havenith et al., 2011; Landry et al., 2011; Leake et al., 2011, 2013; Shibata et al., 2011; van Loon et al., 2013). Although one implication is that SGN death is attributable to NTF deprivation, NTFs rescue neurons from diverse insults, including mitochondrial blockade, excitotoxicity, glucose deprivation, oxidative stress, and hypoxia/ischemia (Frim et al., 1993; Mattson and Cheng, 1993; Mattson et al., 1995; El Idrissi and Trenkner, 1999; Han and Holtzman, 2000; Ikeda et al., 2000; Almeida et al., 2005; Wong et al., 2005; Yoo et al., 2006). For SGNs, FGF has been shown to be protective against excitotoxicity (Zhai et al., 2004). Moreover, high NTF concentrations may have effects different from those of physiological concentrations. Thus, SGN death may be attributable to a cause other than NTF deprivation yet be preventable by high NTF levels. Because NTFs have effects other than preventing apoptosis, not all of which may be desirable, identifying and targeting the proximate cause of SGN death may be more advantageous than use of NTFs.

\section{References}

Adamson CL, Reid MA, Davis RL (2002) Opposite actions of brain-derived neurotrophic factor and neurotrophin-3 on firing features and ion channel composition of murine spiral ganglion neurons. J Neurosci 22:13851396. Medline

Airaksinen MS, Saarma M (2002) The GDNF family: signalling, biological functions and therapeutic value. Nature Rev Neurosci 3:383-394. CrossRef

Alam SA, Robinson BK, Huang J, Green SH (2007) Prosurvival and proapoptotic intracellular signaling in rat spiral ganglion neurons in vivo after the loss of hair cells. J Comp Neurol 503:832-852. CrossRef Medline

Almeida RD, Manadas BJ, Melo CV, Gomes JR, Mendes CS, Grãos MM, Carvalho RF, Carvalho AP, Duarte CB (2005) Neuroprotection by BDNF against glutamate-induced apoptotic cell death is mediated by ERK and PI3-kinase pathways. Cell Death Differ 12:1329-1343. CrossRef Medline

Bao J, Lin H, Ouyang Y, Lei D, Osman A, Kim TW, Mei L, Dai P, Ohlemiller KK, Ambron RT (2004) Activity-dependent transcription regulation of PSD-95 by neuregulin-1 and Eos. Nat Neurosci 7:1250-1258. CrossRef Medline 
Bichler E, Spoendlin H, Rauchegger H (1983) Degeneration of cochlear neurons after amikacin intoxication in the rat. Arch Otorhinolaryngol 237:201-208. CrossRef Medline

Carlier E, Pujol R (1980) Supra-normal sensitivity to ototoxic antibiotic of the developing rat cochlea. Arch Otorhinolaryngol 226:129-133. CrossRef Medline

Dodson HC (1997) Loss and survival of spiral ganglion neurons in the guinea pig after intracochlear perfusion with aminoglycosides. J Neurocytol 26:541-556. CrossRef Medline

El Idrissi A, Trenkner E (1999) Growth factors and taurine protect against excitotoxicity by stabilizing calcium homeostasis and energy metabolism. J Neurosci 19:9459-9468. Medline

Ernfors P, Duan ML, ElShamy WM, Canlon B (1996) Protection of auditory neurons from aminoglycoside toxicity by neurotrophin-3. Nat Med 2:463-467. CrossRef Medline

Flores-Otero J, Xue HZ, Davis RL (2007) Reciprocal regulation of presynaptic and postsynaptic proteins in bipolar spiral ganglion neurons by neurotrophins. J Neurosci 27:14023-14034. CrossRef Medline

Frim DM, Simpson J, Uhler TA, Short MP, Bossi SR, Breakefield XO, Isacson O (1993) Striatal degeneration induced by mitochondrial blockade is prevented by biologically delivered NGF. J Neurosci Res 35:452-458. CrossRef Medline

Fritzsch B, Tessarollo L, Coppola E, Reichardt LF (2004) Neurotrophins in the ear: their roles in sensory neuron survival and fiber guidance. Prog Brain Res 146:265-278. CrossRef Medline

Green SH, Altschuler RA, Miller JM (2008) Cell death and cochlear protection. In: Auditory trauma, protection and repair (Schacht J, Popper AN, Fay RR, eds). New York: Springer.

Green SH, Bailey E, Wang Q, Davis RL (2012) The Trk A, B, C's of neurotrophins in the cochlea. Anat Rec (Hoboken) 295:877-895. CrossRef Medline

Hafidi A, Decourt B, MacLennan AJ (2004) CNTFR $\alpha$ and CNTF expressions in the auditory brainstem: light and electron microscopy study. Hear Res 194:14-24. CrossRef Medline

Han BH, Holtzman DM (2000) BDNF protects the neonatal brain from hypoxic-ischemic injury in vivo via the ERK pathway. J Neurosci 20: 5775-5781. Medline

Hansen MR, Vijapurkar U, Koland JG, Green SH (2001) Reciprocal signaling between spiral ganglion neurons and Schwann cells involves neuregulin and neurotrophins. Hear Res 161:87-98. CrossRef Medline

Hartnick CJ, Staecker H, Malgrange B, Lefebvre PP, Liu W, Moonen G, Van de Water TR (1996) Neurotrophic effects of BDNF and CNTF, alone and in combination, on postnatal day 5 rat acoustic ganglion neurons. J Neurobiol 30:246-254. CrossRef Medline

Havenith S, Versnel H, Agterberg MJ, de Groot JC, Sedee RJ, Grolman W, Klis SF (2011) Spiral ganglion cell survival after round window membrane application of brain-derived neurotrophic factor using gelfoam as carrier. Hear Res 272:168-177. CrossRef Medline

Hegarty JL, Kay AR, Green SH (1997) Trophic support of cultured spiral ganglion neurons by depolarization exceeds and is additive with that by neurotrophins or cyclic AMP, and requires elevation of $\left[\mathrm{Ca}^{2+}\right]_{i}$ within a set range. J Neurosci 17:1959-1970. Medline

Ikeda T, Xia XY, Xia YX, Ikenoue T, Han B, Choi BH (2000) Glial cell line-derived neurotrophic factor protects against ischemia/hypoxiainduced brain injury in neonatal rat. Acta Neuropathol 100:161-167. CrossRef Medline

Kanzaki S, Stöver T, Kawamoto K, Prieskorn DM, Altschuler RA, Miller JM, Raphael Y (2002) Glial cell line-derived neurotrophic factor and chronic electrical stimulation prevent VIII cranial nerve degeneration following denervation. J Comp Neurol 454:350-360. CrossRef Medline

Khimich D, Nouvian R, Pujol R, Tom Dieck S, Egner A, Gundelfinger ED, Moser T (2005) Hair cell synaptic ribbons are essential for synchronous auditory signalling. Nature 434:889-894. CrossRef Medline

Kimitsuki T, Nakashima T, Kawano H, Komune S (2003) Neurotrophin-3 modifies potassium currents in isolated inner hair cells from guinea-pig cochlea. Auris Nasus Larynx 30:141-145. Medline

Koitchev K, Guilhaume A, Cazals Y, Aran JM (1982) Spiral ganglion changes after massive aminoglycoside treatment in the guinea pig. Counts and ultrastructure. Acta Otolaryngol 94:431-438. CrossRef Medline

Kujawa SG, Liberman MC (2006) Acceleration of age-related hearing loss by early noise exposure: evidence of a misspent youth. J Neurosci 26: 2115-2123. CrossRef Medline
Kujawa SG, Liberman MC (2009) Adding insult to injury: cochlear nerve degeneration after "temporary" noise-induced hearing loss. J Neurosci 29:14077-14085. CrossRef Medline

Landry TG, Wise AK, Fallon JB, Shepherd RK (2011) Spiral ganglion neuron survival and function in the deafened cochlea following chronic neurotrophic treatment. Hear Res 282:303-313. CrossRef Medline

Leake PA, Hradek GT (1988) Cochlear pathology of long term neomycin induced deafness in cats. Hear Res 33:11-33. CrossRef Medline

Leake PA, Hradek GT, Hetherington AM, Stakhovskaya O (2011) Brainderived neurotrophic factor promotes cochlear spiral ganglion cell survival and function in deafened, developing cats. J Comp Neurol 519: 1526-1545. CrossRef Medline

Leake PA, Stakhovskaya O, Hetherington A, Rebscher SJ, Bonham B (2013) Effects of brain-derived neurotrophic factor (BDNF) and electrical stimulation on survival and function of cochlear spiral ganglion neurons in deafened, developing cats. J Assoc Res Otolaryngol 14:187-211. CrossRef Medline

Lenoir M, Daudet N, Humbert G, Renard N, Gallego M, Pujol R, Eybalin M, Vago P (1999) Morphological and molecular changes in the inner hair cell region of the rat cochlea after amikacin treatment. J Neurocytol 28: 925-937. CrossRef Medline

Malgrange B, Lefebvre P, Van de Water TR, Staecker H, Moonen G (1996) Effects of neurotrophins on early auditory neurones in cell culture. Neuroreport 7:913-917. CrossRef Medline

Mattson MP, Cheng B (1993) Growth factors protect neurons against excitotoxic/ischemic damage by stabilizing calcium homeostasis. Stroke 24 I136-I140; discussion I144-I145. Medline

Mattson MP, Lovell MA, Furukawa K, Markesbery WR (1995) Neurotrophic factors attenuate glutamate-induced accumulation of peroxides, elevation of intracellular Ca2 + concentration, and neurotoxicity and increase antioxidant enzyme activities in hippocampal neurons. J Neurochem 65:1740-1751. Medline

Nadol JB Jr (1997) Patterns of neural degeneration in the human cochlea and auditory nerve: implications for cochlear implantation. Otolaryngol Head Neck Surg 117:220-228. CrossRef Medline

Nadol JB Jr, Young YS, Glynn RJ (1989) Survival of spiral ganglion cells in profound sensorineural hearing loss: implications for cochlear implantation. Ann Otol Rhinol Laryngol 98:411-416. Medline

Nakaizumi T, Kawamoto K, Minoda R, Raphael Y (2004) Adenovirusmediated expression of brain-derived neurotrophic factor protects spiral ganglion neurons from ototoxic damage. Audiol Neurootol 9:135-143. CrossRef Medline

O’Neil JN, Connelly CJ, Limb CJ, Ryugo DK (2011) Synaptic morphology and the influence of auditory experience. Hear Res 279:118-130. CrossRef Medline

Pirvola U, Ylikoski J, Palgi J, Lehtonen E, Arumäe U, Saarma M (1992) Brain-derived neurotrophic factor and neurotrophin-3 mRNAs in the peripheral target fields of developing inner ear ganglia. Proc Natl Acad Sci U S A 89:9915-9919. CrossRef Medline

Puel JL, Pujol R, Ladrech S, Eybalin M (1991) Alpha-amino-3-hydroxy-5methyl-4-isoxazole propionic acid electrophysiological and neurotoxic effects in the guinea-pig cochlea. Neuroscience 45:63-72. CrossRef Medline

Puel JL, Ruel J, Gervais d'Aldin C, Pujol R (1998) Excitotoxicity and repair of cochlear synapses after noise-trauma induced hearing loss. Neuroreport 9:2109-2114. CrossRef Medline

Pujol R, Lenoir M, Robertson D, Eybalin M, Johnstone BM (1985) Kainic acid selectively alters auditory dendrites connected with cochlear inner hair cells. Hear Res 18:145-151. CrossRef Medline

Rasmussen R (2000) Quantification on the LightCycler. In: Rapid cycle realtime PCR, methods and applications (Meuer S, Wittwer C, Nakagawara K, eds), pp 21-34. Heidelberg: Springer.

Rejali D, Lee VA, Abrashkin KA, Humayun N, Swiderski DL, Raphael Y (2007) Cochlear implants and ex vivo BDNF gene therapy protect spiral ganglion neurons. Hear Res 228:180-187. CrossRef Medline

Rübsamen R, Lippe WR (1998) The development of cochlear function. In: Development of the auditory system (Rubel EW, Popper AN, Fay RR, eds), pp 193-270. New York: Springer.

Schecterson LC, Bothwell M (1994) Neurotrophin and neurotrophin receptor mRNA expression in developing inner ear. Hear Res 73:92-100. CrossRef Medline

Shibata SB, Budenz CL, Bowling SA, Pfingst BE, Raphael Y (2011) Nerve main- 
tenance and regeneration in the damaged cochlea. Hear Res 281:56-64. CrossRef Medline

Spoendlin H (1975) Retrograde degeneration of the cochlear nerve. Acta Otolaryngol 79:266-275. CrossRef Medline

Staecker H, Liu W, Hartnick C, Lefebvre P, Malgrange B, Moonen G, Van de Water TR (1995) NT-3 combined with CNTF promotes survival of neurons in modiolus-spiral ganglion explants. Neuroreport 6:1533-1537. CrossRef Medline

Staecker H, Kopke R, Malgrange B, Lefebvre P, Van de Water TR (1996) NT-3 and/or BDNF therapy prevents loss of auditory neurons following loss of hair cells. Neuroreport 7:889-894. CrossRef Medline

Stöver T, Gong TL, Cho Y, Altschuler RA, Lomax MI (2000) Expression of the GDNF family members and their receptors in the mature rat cochlea. Brain Res Mol Brain Res 76:25-35. CrossRef Medline

Sugawara M, Corfas G, Liberman MC (2005) Influence of supporting cells on neurodegeneration after hair cell loss. J Assoc Res Otolaryngol 6:136147. CrossRef Medline

Sugawara M, Murtie JC, Stankovic KM, Liberman MC, Corfas G (2007) Dynamic patterns of neurotrophin 3 expression in the postnatal mouse inner ear. J Comp Neurol 501:30-37. CrossRef Medline

Tan J, Shepherd RK (2006) Aminoglycoside-induced degeneration of adult spiral ganglion neurons involves differential modulation of tyrosine kinase B and p75 neurotrophin receptor signaling. Am J Pathol 169:528543. CrossRef Medline

Taylor RR, Jagger DJ, Forge A (2012) Defining the cellular environment in the organ of Corti following extensive hair cell loss: a basis for future sensory cell replacement in the cochlea. PLoS One 7:e30577. CrossRef Medline

van Loon MC, Ramekers D, Agterberg MJ, de Groot JC, Grolman W, Klis SF, Versnel H (2013) Spiral ganglion cell morphology in guinea pigs after deafening and neurotrophic treatment. Hear Res 298:17-26. CrossRef Medline

Wang Q, Green SH (2011) Functional role of neurotrophin-3 in synapse regeneration by spiral ganglion neurons on inner hair cells after excitotoxic trauma in vitro. J Neurosci 31:7938-7949. CrossRef Medline

Warnecke A, Scheper V, Buhr I, Wenzel GI, Wissel K, Paasche G, Berkingali N, Jørgensen JR, Lenarz T, Stöver T (2010) Artemin improves survival of spiral ganglion neurons in vivo and in vitro. Neuroreport 21:517-521. CrossRef Medline
Webster M, Webster DB (1981) Spiral ganglion neuron loss following organ of Corti loss: a quantitative study. Brain Res 212:17-30. CrossRef Medline

Wei D, Jin Z, Järlebark L, Scarfone E, Ulfendahl M (2007) Survival, synaptogenesis, and regeneration of adult mouse spiral ganglion neurons in vitro. Dev Neurobiol 67:108-122. CrossRef Medline

Whitlon DS, Grover M, Tristano J, Williams T, Coulson MT (2007) Culture conditions determine the prevalence of bipolar and monopolar neurons in cultures of dissociated spiral ganglion. Neuroscience 146:833-840. CrossRef Medline

Wong LF, Ralph GS, Walmsley LE, Bienemann AS, Parham S, Kingsman SM, Uney JB, Mazarakis ND (2005) Lentiviral-mediated delivery of Bcl-2 or GDNF protects against excitotoxicity in the rat hippocampus. Mol Ther 11:89-95. CrossRef Medline

Yagi M, Kanzaki S, Kawamoto K, Shin B, Shah PP, Magal E, Sheng J, Raphael Y (2000) Spiral ganglion neurons are protected from degeneration by GDNF gene therapy. J Assoc Res Otolaryngol 1:315-325. CrossRef Medline

Ylikoski J, Pirvola U, Moshnyakov M, Palgi J, Arumäe U, Saarma M (1993) Expression patterns of neurotrophin and their receptor mRNAs in the rat inner ear. Hear Res 65:69-78. CrossRef Medline

Ylikoski J, Pirvola U, Virkkala J, Suvanto P, Liang XQ, Magal E, Altschuler R, Miller JM, Saarma M (1998) Guinea pig auditory neurons are protected by glial cell line-derived growth factor from degeneration after noise trauma. Hear Res 124:17-26. CrossRef Medline

Yoo YM, Lee CJ, Lee U, Kim YJ (2006) Neuroprotection of adenoviralvector-mediated GDNF expression against kainic-acid-induced excitotoxicity in the rat hippocampus. Exp Neurol 200:407-417. CrossRef Medline

Zha X.-M, Bishop JF, Hansen MR, Victoria L, Abbas PJ, Mouradian MM, Green SH (2001) BDNF synthesis in spiral gangion neurons is constitutive and CREB-dependent. Hear Res 156:53-68. CrossRef Medline

Zhai SQ, Wang DJ, Wang JL, Han DY, Yang WY (2004) Basic fibroblast growth factor protects auditory neurons and hair cells from glutamate neurotoxicity and noise exposure. Acta Otolaryngol 124:124-129. CrossRef Medline

Zilberstein Y, Liberman MC, Corfas G (2012) Inner hair cells are not required for survival of spiral ganglion neurons in the adult cochlea. J Neurosci 32:405-410. CrossRef Medline 